\title{
Construction and Validation of New Nomograms to Predict Risk and Prognostic Factors of Breast Cancer Bone Metastasis in Asian Females: A Population-Based Retrospective Study
}

Junsen Deng',*

Di Zhang ${ }^{2, *}$

Wenming Zhang'

Junhui $\mathrm{Li}^{2}$

'Department of Orthopedics Surgery, Luoyang Orthopedic Hospital of Henan Province, Orthopedic Hospital of Henan Province, Zhengzhou, 45000, Henan, People's Republic of China; ${ }^{2}$ Department of Spine Surgery, Luoyang Orthopedic Hospital of Henan Province, Orthopedic Hospital of Henan Province, Zhengzhou, 45000, Henan, People's Republic of China

*These authors contributed equally to this work
Correspondence: Junsen Deng Department of Orthopedics Surgery, Luoyang Orthopedic Hospital of Henan Province, Orthopedic Hospital of Henan Province, Zhengzhou, 45000, Henan, People's Republic of China Email djstougao@I26.com
Purpose: To construct a breast cancer bone-only metastasis (BCBM) risk and prognostic model for Asian females and provide a reference for treatment selection in breast cancer (BC) patients with bone-only metastasis (BM).

Patients and Methods: The data for newly diagnosed female patients of Asian Pacific Islander (API) ethnicity between 2010 and 2018 were obtained from the Surveillance, Epidemiology, and End Results database. A total of 16,972 patients were identified. Logistic regression analyses were used to establish a risk model for BCBM. Cox proportional hazards regression analyses were used to construct nomograms for the prognosis of $\mathrm{BC}$ and BCBM. Subsequently, the degree of discrimination of the nomogram was evaluated using the consistency index (C-index) and receiver operating curve.

Results: The main independent risk factors of BM in Asian females with $\mathrm{BC}$ were primary site surgery $(p<0.0001)$, ER $(p=0.0015)$, and T-stage $(p=0.0046)$. The $C$-index values in the training and validation cohorts were 0.933 and 0.941 , respectively. The main independent risk factors of the prognosis of $B C$ were age $(p<0.001)$, summary stage $(p<0.001)$, and grade $(\mathrm{p}=0.002)$. The $\mathrm{C}$-index values of 5 -year overall survival (OS) in the training and validation cohorts were 0.823 and 0.804 , respectively. The risk factors of the prognosis of Asian females with BCBM were subtype $(p<0.001)$, histology $(p<0.001)$, and grade $(p=0.033)$. The C-index values of 5-year OS in the training and validation cohorts were 0.793 and 0.723 , respectively.

Conclusion: Using population-based analysis, this study constructed a prediction model for the risk and prognosis of BM in Asian females with BC. Another newly constructed model was effective in predicting OS in BCBM patients. These models can help prevent skeletalrelated events and weigh the risks and benefits of surgery for metastatic lesions in BCBM patients.

Keywords: breast cancer, bone metastasis, prognosis, nomogram, SEER

\section{Introduction}

More than 1.6 million people are diagnosed with breast cancer (BC) every year in China, and 1.2 million people die from this disease. ${ }^{1}$ Distant metastasis is a major cause of death in patients with BC. It is currently recognized that the most common sites of $\mathrm{BC}$ metastasis are the lungs, bone, liver, and brain. ${ }^{2}$ Among them, bone is the most frequent metastatic site of advanced $\mathrm{BC}$, and bone metastases accounting 


\section{Graphical Abstract}

A

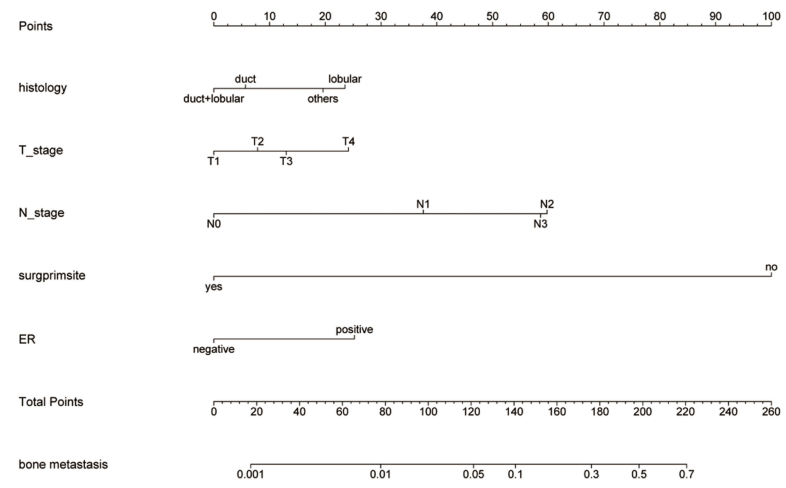

B

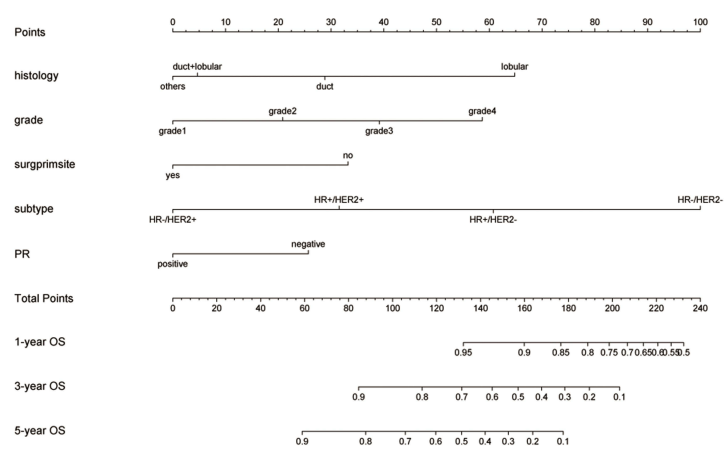

for $70 \%$ of distant BC metastases. ${ }^{3}$ Tumor cells can spread from the primary $\mathrm{BC}$ site and metastasize to the bone microenvironment. Irf7-mediated immune escape and CD137-related migration and osteoclast differentiation of monocytes/macrophages may be important mechanisms that promote the occurrence of bone metastases in BC. ${ }^{4-6}$ Breast cancer bone metastases can easily cause skeletalrelated events (SREs) that seriously affect the quality of life of patients and increase the social burden. ${ }^{7}$ Early detection of bone metastases is very important to prevent SREs. In general, systematic conservative treatment is preferred when dealing with multiple distant metastases of breast cancer, but whether patients with single bone metastasis can be surgically treated for metastatic lesions is still inconclusive. ${ }^{8}$ When choosing a treatment, the patient's expected survival time is one of the most important factors that must be considered. Therefore, exploring the relevant factors affecting the prognosis of patients with $\mathrm{BCBM}$ is important to the formulation of subsequent treatment strategies. Previous studies have shown that race is an independent risk factor that affects the occurrence and prognosis of breast cancer bone metastases. ${ }^{9,10}$ Therefore, the establishment of risk and prognostic models for Asian females with BCBM is conducive to more precise and individualized prevention and treatment of this disease.

A nomogram is a graphical tool developed in the 19th century. By integrating different prognostic and determinative variables, individual probabilities of clinical events are generated to aid clinical decision-making and realize the pursuit of personalized medicine. ${ }^{11}$ Currently, nomograms are widely used in oncology and medical practice and have achieved good results. ${ }^{12,13}$ There are many prediction models for the risk and prognosis of breast cancer bone metastasis, but these models were either not based on Asian females or did not exclude multiple organ metastases. ${ }^{9,14}$ However, to our knowledge, there is currently no specific prediction model or nomogram for the risk of bone-only metastasis nor for the prognostic value of BCBM in Asian females.

In this study, we extracted complete data on 16,972 Asian breast cancer patients from the Surveillance, Epidemiology, and End Results (SEER) database and established prediction models for BCBM and BC prognosis in the training cohort. The prediction models were validated in the validation cohort to determine their predictive capability. Furthermore, the same method was used to establish and validate a prognostic prediction model for the BCBM cohort.

\section{Materials and Methods Data Collection}

The SEER database is an authoritative cancer statistical database in the United States, covering about $28 \%$ of cancer registrations in the United States and containing records of the morbidity, mortality, and other information of millions of cancer patients in the United States. ${ }^{15}$ Before starting this research, we submitted a data usage agreement to the SEER project and gained formal access to the database. Because the database is open and this was a retrospective study, this study did not require the approval of the institutional research ethics committee, 
nor did it require additional informed consent. We used the SEER*Stat software (version 8.3.9, user name: 11,532Nov 2020) to extract data from the SEER database. The data included females who were newly diagnosed with BC between 2010 and 2018 and were of the Asian/Pacific Islander (API) ethnicity. The inclusion criteria were: (1) $\mathrm{BC}$ as the first primary tumor; (2) patients diagnosed with BC using histology or cytology; and (3) patients with complete clinicopathological characteristics, demographic information, and follow-up information. The exclusion criteria were patients with: (1) multiple organ metastasis; (2) patients with $\mathrm{T} 0$ or unknown T_stage status; (3) patients with autopsy or death certificate; or (4) patients with follow-up time $<6$ months. A total of 16,972 patients were included in the study, of which 11,918 cases were used as a training cohort to construct prediction models and nomograms, and 5054 as a validation cohort to verify the constructed prediction models and nomograms. Subsequently, extracted patients with bone-only metastasis ( $n=223$ cases) were used to constructed and validated the Cox proportional hazard model and nomogram according to the aforementioned method. A flowchart of this process is shown in Figure 1A.

\section{Variable Selection}

In this study, the following parameters were included: the patient's age, primary tumor site, laterality, histology, tumor grade, summary stage, $\mathrm{T}$ - and $\mathrm{N}$-stage, tumor size, and breast cancer subtype; bone, lung, liver, and brain metastasis; estrogen receptor (ER), progesterone receptor
A

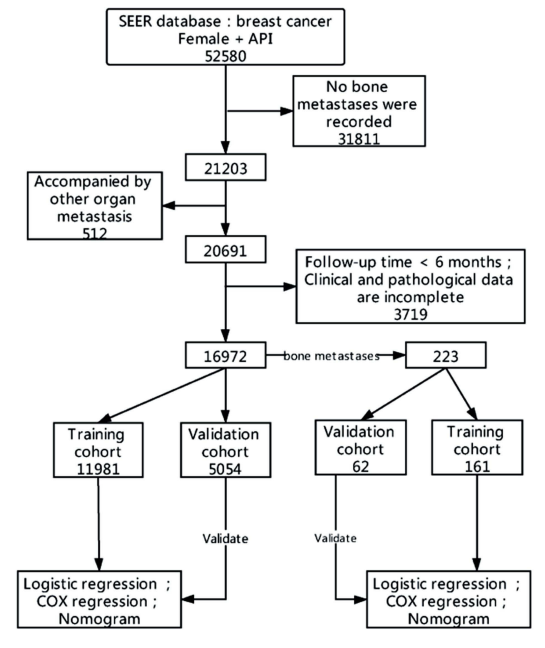

C

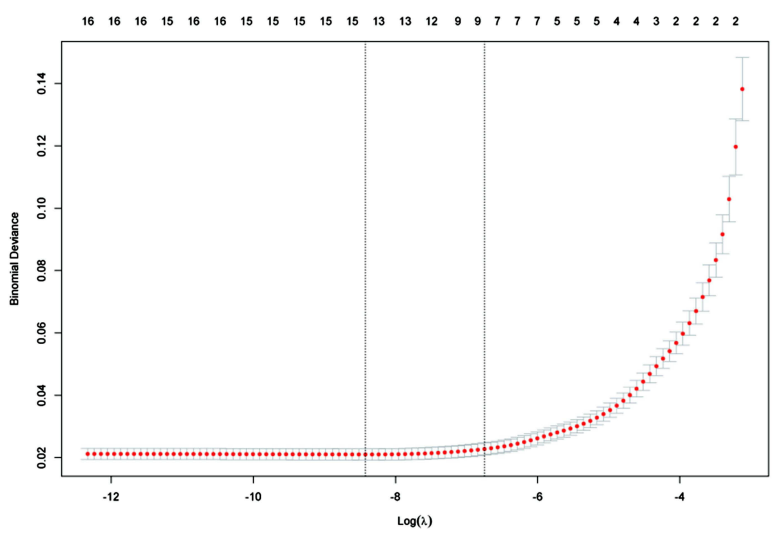

B

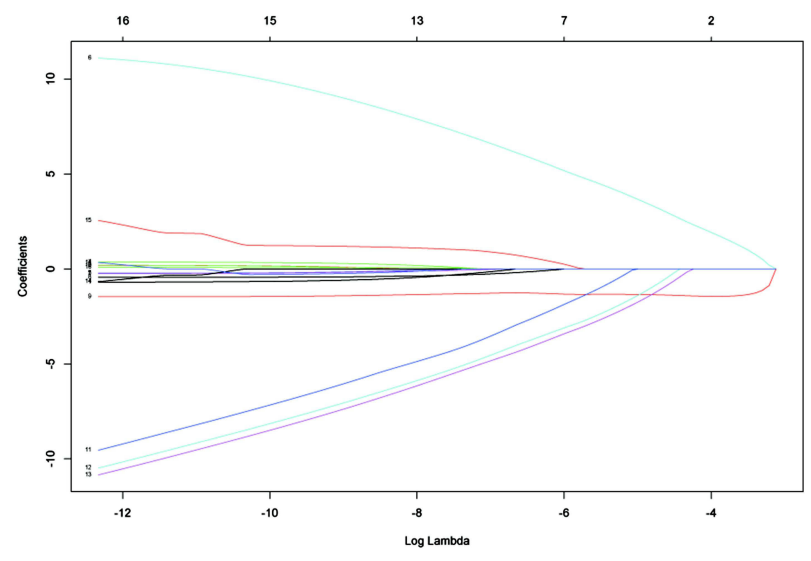

D

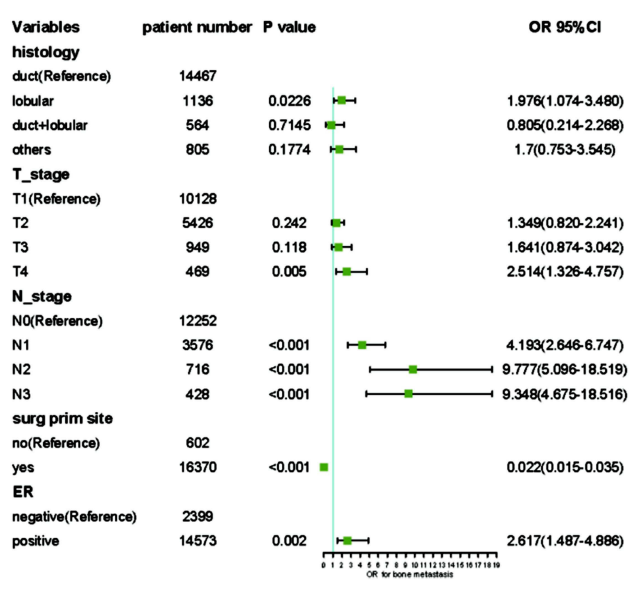

Figure I The flow chart and the screening of BCBM related variables. (A) The flow chart. There are 16,972 patients included in this study based on the inclusion and exclusion criteria. (B and C) LASSO regression is used to screen variables. (D) Forest plots are used to delineate the independent risk factors of BCBM. Abbreviations: API, Asian, Pacific Islander; ER, estrogen receptor. 
(PR), and human epidermal growth factor receptor 2 (HER2) status; whether to undergo surgery at the primary site; survival time; and life status. The cutoff age was determined using the X-Tile software (version 3.6.1, https://medicine.yale.edu/lab/rimm/research/software/),

and three age groups were formed $(<64,64-76,>76$ years). The primary breast tumor site was divided into six categories according to the International Classification Code of Tumor Diseases (nipple/central part, upper inner quadrant, lower inner quadrant, upperouter quadrant, and lower outer quadrant, and other parts of the breast). Histology types were divided into four categories: ductal carcinoma, lobular carcinoma, ductal carcinoma + lobular carcinoma, and others). The grade of tumor differentiation was divided into four groups: grade I, grade II, grade III, and grade IV. Tumor size was divided into 3 groups $(<2 \mathrm{~cm}, 2-5 \mathrm{~cm},>5 \mathrm{~cm})$. Breast cancer subtypes include four types (hormone receptor (HR)-/HER2-, HR-/HER2+, HR+/HER2-, HR+/HER2 + ). All cases in this study were staged according to the seventh edition of the TNM staging system.

\section{Statistical Analysis}

Using R (version 3.6.3, https://www.r-project.org/) for statistical analysis, a p-value of $<0.05$ was considered statistically significant. First, the study cohort was randomly divided into training cohort and validation cohorts at a ratio of 7:3, and a chi-square test was performed on the categorical variables between the training and validation cohorts. The "rms" package and "glmnet" package were used to perform univariate logistic regression analysis and least absolute shrinkage and selection operator (LASSO) regression in the training cohort ${ }^{16}$ to screen out variables that may be related to BCBM. Then the "MASS" package was used to perform backward stepwise regression, the Akaike information criterion (AIC) as a stopping rule, to determine the variables that will eventually be included in the regression model. ${ }^{17}$ The selected variables were included in the multivariate logistic regression analysis to determine the independent risk factors for $\mathrm{BCBM}$ and construct a nomogram. The C-index and ROC were used to evaluate the discrimination of the nomogram, and bootstraps with 1000 resample were used to verify the calibration of the nomogram and draw the calibration curve. ${ }^{18}$ The same method was used to construct a Cox proportional hazard model for Asian female BC patients, and to evaluate the performance of the model. Overall survival (OS) that referred to the period from random assignment to death due to any reason, was estimated by KaplanMeier survival curves. A Log rank test was used to compare the survival curves.

A total of $233 \mathrm{BC}$ patients with bone-only metastases were extracted, and the same method was used to establish and validate the prognostic prediction model based on this cohort.

\section{Result}

\section{Baseline Characteristics}

All patients with $\mathrm{BC}$ were female, and their ethnicity was API. The median age of the entire cohort was 59.00 $(49.00,68.00)$ years. The most common tumor site was upper-outer $(\mathrm{n}=5575 ; 32.8 \%)$. The incidences of the left and right breasts were almost the same: 8465 (49.9\%) and 8507 (50.1\%), respectively. The most common type of histology was infiltrating duct carcinoma ( $n=14,467$; $85.2 \%$ ). Tumor grade II was the most common at 7803 (46\%), followed by grade III at 5030 (29.6\%). In the tumor summary stage, local tumors accounted for 11,925 patients $(70.3 \%)$. The most frequent TNM stages were T1 $10,128(59.7 \%)$ and N0 12,252 (72.2\%). Primary tumor surgeries were performed on 16,370 patients, accounting for $96.5 \%$. There were 9558 patients with a tumor size $<$ $2 \mathrm{~cm}$, accounting for $56.3 \%$. Bone metastases occurred in 223 patients in the entire cohort, with an incidence rate of $1.3 \%$. Among the BC subtypes, HR+/HER2- was the most common type $(n=12,866 ; 75.8 \%)$. The ratio of ER and PR positivity was far higher than that of negativity, whereas the status of HER2 was the opposite. The baseline data of the training and validation cohorts were balanced and comparable (Table 1).

Among the 223 patients with bone metastases, the median age was $56.00(45.00,65.00)$. The most common tumor site was "others" ( $\mathrm{n}=106 ; 47.5 \%)$. The most common TNM stages were T2 $82(36.8 \%)$ and N1 117 $(52.5 \%)$. There were 145 cases without primary site surgery, accounting for $65 \%$ of the cases. There were 101 cases with tumor sizes of $2-5 \mathrm{~cm}$, accounting for $45.5 \%$. The characteristics of the remaining variables were similar to those of the entire cohort. The baseline data of the training and validation cohorts were balanced and comparable (Table 2).

\section{Independent Predictors for BCBM in the Training Cohort}

In univariate analysis, tumor site, histology, grade, T-stage, $\mathrm{N}$-stage, primary site surgery, tumor size, BC subtype, and 
Table I Clinical and Pathological Features of Patients in the Study Cohort

\begin{tabular}{|c|c|c|c|c|}
\hline \multirow[t]{2}{*}{ Variables } & Total Cohort & Training Cohort & Validation Cohort & \multirow[t]{2}{*}{$\mathbf{p}$} \\
\hline & $n=16,972$ & $n=11,918$ & $n=5054$ & \\
\hline \multicolumn{5}{|l|}{ Age (\%) } \\
\hline$<64$ years & $10,656(62.8)$ & 7477 (62.7) & $3179(62.9)$ & \multirow[t]{3}{*}{0.521} \\
\hline $64-76$ years & $4532(26.7)$ & 3205 (26.9) & $1327(26.3)$ & \\
\hline$>76$ years & $1784(10.5)$ & $1236(10.4)$ & $548(10.8)$ & \\
\hline \multicolumn{5}{|c|}{ Tumour site (\%) } \\
\hline Npple/central & $959(5.7)$ & $676(5.7)$ & $283(5.6)$ & \multirow[t]{6}{*}{0.766} \\
\hline Upper-inner & $2620(15.4)$ & $1857(15.6)$ & $763(15.1)$ & \\
\hline Lower-inner & $945(5.6)$ & $659(5.5)$ & $286(5.7)$ & \\
\hline Upper-outer & 5575 (32.8) & $3883(32.6)$ & $1692(33.5)$ & \\
\hline Lower-outer & $|27|(7.5)$ & $909(7.6)$ & $362(7.2)$ & \\
\hline Others & $5602(33.0)$ & $3934(33.0)$ & $1668(33.0)$ & \\
\hline \multicolumn{5}{|c|}{ Laterality (\%) } \\
\hline Left & 8465 (49.9) & $5898(49.5)$ & $2567(50.8)$ & \multirow[t]{2}{*}{0.125} \\
\hline Right & 8507 (50.1) & $6020(50.5)$ & 2487 (49.2) & \\
\hline \multicolumn{5}{|c|}{ Histology (\%) } \\
\hline Duct & 14,467 (85.2) & $10,135(85.0)$ & $4332(85.7)$ & \multirow[t]{4}{*}{0.631} \\
\hline Lobular & $1136(6.7)$ & $803(6.7)$ & $333(6.6)$ & \\
\hline Duct+lobular & $564(3.3)$ & $400(3.4)$ & $164(3.2)$ & \\
\hline Others & $805(4.7)$ & $580(4.9)$ & $225(4.5)$ & \\
\hline \multicolumn{5}{|l|}{ Grade (\%) } \\
\hline Gradel & $4106(24.2)$ & $2867(24.1)$ & $1239(24.5)$ & \multirow[t]{4}{*}{0.217} \\
\hline Grade2 & $7803(46.0)$ & $5500(46.1)$ & $2303(45.6)$ & \\
\hline Grade3 & $5030(29.6)$ & $3533(29.6)$ & $1497(29.6)$ & \\
\hline Grade4 & $33(0.2)$ & $18(0.2)$ & $15(0.3)$ & \\
\hline \multicolumn{5}{|c|}{ Summary stage (\%) } \\
\hline Local & II,925 (70.3) & $8355(70.1)$ & $3570(70.6)$ & \multirow[t]{3}{*}{0.66} \\
\hline Regional & $4645(27.4)$ & $3274(27.5)$ & $|37|(27.1)$ & \\
\hline Distant & $402(2.4)$ & $289(2.4)$ & $113(2.2)$ & \\
\hline \multicolumn{5}{|l|}{ T_stage (\%) } \\
\hline TI & $10,128(59.7)$ & $7096(59.5)$ & $3032(60.0)$ & \multirow[t]{4}{*}{0.939} \\
\hline $\mathrm{T} 2$ & $5426(32.0)$ & $3818(32.0)$ & $1608(31.8)$ & \\
\hline T3 & $949(5.6)$ & $672(5.6)$ & $277(5.5)$ & \\
\hline $\mathrm{T} 4$ & $469(2.8)$ & $332(2.8)$ & $137(2.7)$ & \\
\hline \multicolumn{5}{|l|}{ N_stage (\%) } \\
\hline No & 12,252 (72.2) & $8592(72.1)$ & $3660(72.4)$ & \multirow[t]{4}{*}{0.852} \\
\hline NI & $3576(21.1)$ & $2526(21.2)$ & $1050(20.8)$ & \\
\hline N2 & $716(4.2)$ & $496(4.2)$ & $220(4.4)$ & \\
\hline N3 & $428(2.5)$ & $304(2.6)$ & $124(2.5)$ & \\
\hline \multicolumn{5}{|c|}{ Surg prim site (\%) } \\
\hline No & $602(3.5)$ & $425(3.6)$ & $177(3.5)$ & \multirow[t]{2}{*}{0.873} \\
\hline Yes & 16,370 & II,493 (96.4) & 4877 (96.5) & \\
\hline
\end{tabular}


Table I (Continued).

\begin{tabular}{|c|c|c|c|c|}
\hline \multirow[t]{2}{*}{ Variables } & Total Cohort & Training Cohort & Validation Cohort & \multirow[t]{2}{*}{$\mathbf{p}$} \\
\hline & $n=16,972$ & $n=11,918$ & $n=5054$ & \\
\hline \multicolumn{5}{|l|}{ Tumour size (\%) } \\
\hline$<2 \mathrm{~cm}$ & $9558(56.3)$ & $6689(56.1)$ & $2869(56.8)$ & \multirow[t]{3}{*}{0.719} \\
\hline $2 \sim 5 \mathrm{~cm}$ & $6070(35.8)$ & $4285(36.0)$ & 1785 (35.3) & \\
\hline$>5 \mathrm{~cm}$ & $1343(7.9)$ & $943(7.9)$ & $400(7.9)$ & \\
\hline \multicolumn{5}{|l|}{ Bone_metastasis (\%) } \\
\hline No & 16,749 (98.7) & II,759 (98.7) & 4990 (98.7) & \multirow[t]{2}{*}{0.779} \\
\hline Yes & $223(1.3)$ & $159(1.3)$ & $64(1.3)$ & \\
\hline \multicolumn{5}{|l|}{ Brain_metastasis (\%) } \\
\hline No & $16,966(100.0)$ & $11,912(99.9)$ & $5054(100.0)$ & \multirow[t]{2}{*}{0.251} \\
\hline Yes & $6(0.0)$ & $6(0.1)$ & $0(0.0)$ & \\
\hline \multicolumn{5}{|l|}{ Liver_metastasis (\%) } \\
\hline No & 16,948 (99.9) & II,902 (99.9) & $5046(99.8)$ & \multirow[t]{2}{*}{0.875} \\
\hline Yes & $24(0.1)$ & $16(0.1)$ & $8(0.2)$ & \\
\hline \multicolumn{5}{|l|}{ Lung_metastasis (\%) } \\
\hline No & 16,922 (99.7) & II,882 (99.7) & 5040 (99.7) & \multirow[t]{2}{*}{0.904} \\
\hline Yes & $50(0.3)$ & $36(0.3)$ & $14(0.3)$ & \\
\hline \multicolumn{5}{|l|}{ Subtype (\%) } \\
\hline HR-/HER2- & $1396(8.2)$ & $991(8.3)$ & $405(8.0)$ & \multirow[t]{4}{*}{0.503} \\
\hline HR-/HER2+ & $869(5.1)$ & $607(5.1)$ & $262(5.2)$ & \\
\hline HR+/HER2- & $12,866(75.8)$ & $9003(75.5)$ & $3863(76.4)$ & \\
\hline $\mathrm{HR}+/ \mathrm{HER} 2+$ & $184 \mid(10.8)$ & $1317(11.1)$ & $524(10.4)$ & \\
\hline \multicolumn{5}{|l|}{ ER (\%) } \\
\hline Negative & $2399(14.1)$ & $1698(14.2)$ & 701 (13.9) & \multirow[t]{2}{*}{0.535} \\
\hline Positive & 14,573 (85.9) & $10,220(85.8)$ & $4353(86.1)$ & \\
\hline \multicolumn{5}{|l|}{ PR (\%) } \\
\hline Negative & $4092(24.1)$ & $2876(24.1)$ & $1216(24.1)$ & \multirow[t]{2}{*}{0.936} \\
\hline Positive & 12,880 (75.9) & $9042(75.9)$ & 3838 (75.9) & \\
\hline \multicolumn{5}{|l|}{ HER2 (\%) } \\
\hline Negative & $14,262(84.0)$ & 9994 (83.9) & $4268(84.4)$ & \multirow[t]{2}{*}{0.348} \\
\hline Positive & $2710(16.0)$ & $1924(16.1)$ & $786(15.6)$ & \\
\hline Month (median [IQR]) & $47.00[25.00,72.00]$ & $46.00[24.00,72.00]$ & $48.00[25.00,73.00]$ & 0.039 \\
\hline
\end{tabular}

Abbreviations: HER2, human epidermal growth factor receptor 2; ER, estrogen receptor; PR, progesterone receptor.

ER were related to BCBM $(\mathrm{p}<0.05)$. In LASSO regression, 1se was selected as the optimal lambda value to screen out age, histology, primary site surgery, ER, and $\mathrm{N}$-stage (Figures $1 \mathrm{~B}$ and $\mathrm{C}$ ). Considering the results of backward stepwise regression and the clinical significance of the variables, histology, T-stage, N-stage, primary site surgery, and ER were finally included in the multivariate logistic regression model. Multivariate logistics regression analysis of the training cohort also showed that the independent risk factors for BCBM were histology (lobular vs duct, $\mathrm{OR}=1.976,95 \% \mathrm{CI}=1.074-3.480, \mathrm{p}=0.0226$ ), T-stage (T4 vs T1, OR $=2.514,95 \% \mathrm{CI}=1.326-4.757, \mathrm{p}$ $=0.0046), \mathrm{N}$-stage $(\mathrm{N} 1$ vs $\mathrm{N} 0, \mathrm{OR}=4.193,95 \% \mathrm{CI}=$ 2.646-6.747, $\mathrm{p}<0.0001 ; \mathrm{N} 2$ vs N0, OR $=9.778,95 \%$ CI 
Table 2 Clinical and Pathological Features of BCBM Patients in the Study Cohort

\begin{tabular}{|c|c|c|c|c|}
\hline \multirow[t]{2}{*}{ Variables } & Total Cohort & Training Cohort & Validation Cohort & p \\
\hline & $\mathrm{n}=\mathbf{2 2 3}$ & $n=161$ & $n=62$ & \\
\hline \multicolumn{5}{|l|}{ Age (\%) } \\
\hline$<64$ years & $|5|(67.7)$ & $106(65.8)$ & $45(72.6)$ & \multirow[t]{3}{*}{0.234} \\
\hline $64-76$ years & $56(25.1)$ & $45(28.0)$ & II (17.7) & \\
\hline$>76$ years & $16(7.2)$ & $10(6.2)$ & $6(9.7)$ & \\
\hline \multicolumn{5}{|c|}{ Tumour site (\%) } \\
\hline Npple/central & $21(9.4)$ & $16(9.9)$ & $5(8.1)$ & \multirow[t]{6}{*}{0.808} \\
\hline Upper-inner & $26(11.7)$ & $21(13.0)$ & $5(8.1)$ & \\
\hline Lower-inner & $7(3.1)$ & $5(3.1)$ & $2(3.2)$ & \\
\hline Upper-outer & $48(21.5)$ & $34(21.1)$ & $14(22.6)$ & \\
\hline Lower-outer & $15(6.7)$ & $9(5.6)$ & $6(9.7)$ & \\
\hline Others & $106(47.5)$ & $76(47.2)$ & $30(48.4)$ & \\
\hline \multicolumn{5}{|c|}{ Laterality (\%) } \\
\hline Left & $110(49.3)$ & $87(54.0)$ & $23(37.1)$ & \multirow[t]{2}{*}{0.034} \\
\hline Right & $113(50.7)$ & $74(46.0)$ & $39(62.9)$ & \\
\hline \multicolumn{5}{|l|}{ Histology (\%) } \\
\hline Duct & $173(77.6)$ & $125(77.6)$ & $48(77.4)$ & \multirow[t]{4}{*}{0.855} \\
\hline Lobular & $27(12.1)$ & $19(11.8)$ & $8(12.9)$ & \\
\hline Duct+lobular & $7(3.1)$ & $6(3.7)$ & $I(1.6)$ & \\
\hline Others & $16(7.2)$ & II (6.8) & $5(8.1)$ & \\
\hline \multicolumn{5}{|l|}{ Grade (\%) } \\
\hline Gradel & $21(9.4)$ & $13(8.1)$ & $8(12.9)$ & \multirow[t]{4}{*}{0.496} \\
\hline Grade2 & III (49.8) & $80(49.7)$ & $31(50.0)$ & \\
\hline Grade3 & $88(39.5)$ & $65(40.4)$ & $23(37.1)$ & \\
\hline Grade4 & $3(1.3)$ & $3(1.9)$ & $0(0.0)$ & \\
\hline \multicolumn{5}{|c|}{ Summary stage (\%) } \\
\hline Regional & I (0.4) & I (0.6) & $0(0.0)$ & \multirow[t]{2}{*}{1} \\
\hline Distant & $222(99.6)$ & $160(99.4)$ & $62(100.0)$ & \\
\hline \multicolumn{5}{|l|}{ T_stage (\%) } \\
\hline TI & $40(17.9)$ & $30(18.6)$ & $10(16.1)$ & \multirow[t]{4}{*}{0.849} \\
\hline T2 & $82(36.8)$ & $61(37.9)$ & $21(33.9)$ & \\
\hline T3 & $37(16.6)$ & $26(16.1)$ & II (17.7) & \\
\hline T4 & 64 (28.7) & $44(27.3)$ & $20(32.3)$ & \\
\hline \multicolumn{5}{|l|}{ N_stage (\%) } \\
\hline No & 44 (19.7) & $27(16.8)$ & $17(27.4)$ & \multirow[t]{4}{*}{0.328} \\
\hline $\mathrm{NI}$ & $117(52.5)$ & $87(54.0)$ & $30(48.4)$ & \\
\hline N2 & $28(12.6)$ & $22(13.7)$ & $6(9.7)$ & \\
\hline N3 & $34(15.2)$ & $25(15.5)$ & $9(14.5)$ & \\
\hline \multicolumn{5}{|c|}{ Surgprimsite (\%) } \\
\hline No & $145(65.0)$ & $109(67.7)$ & $36(58.1)$ & \multirow[t]{2}{*}{0.232} \\
\hline Yes & $78(35.0)$ & $52(32.3)$ & $26(41.9)$ & \\
\hline
\end{tabular}


Table 2 (Continued).

\begin{tabular}{|c|c|c|c|c|}
\hline \multirow[t]{2}{*}{ Variables } & Total Cohort & Training Cohort & Validation Cohort & $\mathbf{p}$ \\
\hline & $n=223$ & $n=161$ & $n=62$ & \\
\hline \multicolumn{5}{|l|}{ Tumoursize (\%) } \\
\hline$<2 \mathrm{~cm}$ & $4 \mid(18.4)$ & $27(16.8)$ & $14(22.6)$ & 0.565 \\
\hline $2 \sim 5 \mathrm{~cm}$ & $102(45.7)$ & $74(46.0)$ & $28(45.2)$ & \\
\hline$>5 \mathrm{~cm}$ & $80(35.9)$ & $60(37.3)$ & $20(32.3)$ & \\
\hline \multicolumn{5}{|l|}{ Subtype (\%) } \\
\hline HR-/HER2- & $12(5.4)$ & $10(6.2)$ & $2(3.2)$ & 0.069 \\
\hline HR-/HER2+ & $10(4.5)$ & $5(3.1)$ & $5(8.1)$ & \\
\hline HR+/HER2- & $167(74.9)$ & $126(78.3)$ & $4 I(66.1)$ & \\
\hline $\mathrm{HR}+/ \mathrm{HER} 2+$ & $34(15.2)$ & $20(12.4)$ & $14(22.6)$ & \\
\hline \multicolumn{5}{|l|}{ ER (\%) } \\
\hline Negative & $22(9.9)$ & $15(9.3)$ & $7(11.3)$ & 0.848 \\
\hline Positive & $201(90.1)$ & $146(90.7)$ & $55(88.7)$ & \\
\hline \multicolumn{5}{|l|}{ PR (\%) } \\
\hline Negative & $52(23.3)$ & $40(24.8)$ & $12(19.4)$ & 0.489 \\
\hline Positive & $|7|$ (76.7) & $12 \mid(75.2)$ & $50(80.6)$ & \\
\hline \multicolumn{5}{|l|}{ HER2 (\%) } \\
\hline Negative & $179(80.3)$ & $136(84.5)$ & $43(69.4)$ & 0.019 \\
\hline Positive & 44 (19.7) & $25(15.5)$ & $19(30.6)$ & \\
\hline Month (median [IQR]) & $29.00[16.00,46.00]$ & $30.00[16.00,46.00]$ & $24.00[16.00,49.00]$ & 0.649 \\
\hline
\end{tabular}

Abbreviations: HER2, human epidermal growth factor receptor 2; ER, estrogen receptor; PR, progesterone receptor.

$=5.096-18.519, \mathrm{p}<0.0001 ; \mathrm{N} 3$ vs N0, OR $=9.348,95 \%$ $\mathrm{CI}=4.675-18.516, \mathrm{p}<0.0001)$, primary site surgery (yes vs no, $\mathrm{OR}=0.022,95 \% \mathrm{CI}=0.015-0.033, \mathrm{p}<0.0001$ ), and $\mathrm{ER}$ (positive vs negative, $\mathrm{OR}=2.617,95 \% \mathrm{CI}=$ 1.4867-4.886, $\mathrm{p}=0.0015$ ) (Table 3, Figure 1D).

\section{The Established and Validated Nomogram for BCBM in Asian Females}

The nomogram was constructed based on variables previously screened in the training cohort. It can be seen from the nomogram that when surgery was performed at the primary site, it had the greatest impact on the occurrence of BCBM, followed by the N-stage (Figure 2). We can sum the scores of each variable and draw a straight line to obtain the probability of BCBM for each patient. The $\mathrm{C}$-index was used to evaluate the degree of discrimination of the nomogram in the training and validation cohorts. The C-indexes in the training and validation cohorts were $0.933(95 \% \mathrm{CI}=0.911-0.955)$ and $0.941(95 \% \mathrm{CI}=$ $0.917-0.965)$, respectively. In visualizing the results with
ROC, the abscissa represents the false positive rate, the ordinate the true positive rate, and the area under the curve the C-index (Figures 3A and B). A calibration curve was used to evaluate the calibration of the nomogram in the training and validation cohorts. The abscissa represents the nomogram-predicted probability of bone metastasis, and the ordinate represents the actual bone metastasis. The closer the curve is to the dashed line with a slope of $45^{\circ}$, the higher the calibration of the nomogram. It can be seen that the actual probability and predicted probability of bone metastasis are in agreement in both the training and validation cohorts (Figures $3 \mathrm{C}$ and $\mathrm{D}$ ).

\section{The Established and Validated Prediction Model for the Prognosis of BC}

According to the aforementioned variables, age, grade, summary stage, T-stage, $\mathrm{N}$-stage, primary site surgery, $\mathrm{BC}$ subtype, and ER were finally included in the multivariate Cox proportional hazard model (Figures $4 \mathrm{~A}$ and $\mathrm{B}$ ). The results showed that these variables were independent risk 
Table 3 Univariate and Multivariate Logistic Regression Analysis of Risk Factor of Bone Metastasis in Training Cohort

\begin{tabular}{|c|c|c|c|c|c|c|}
\hline \multirow[t]{2}{*}{ Variables } & \multicolumn{3}{|c|}{ Univariate Logistic Regression } & \multicolumn{3}{|c|}{ Multivariate Logistic Regression } \\
\hline & OR & $95 \% \mathrm{Cl}$ & $\mathbf{P}$ & OR & $95 \% \mathrm{Cl}$ & $\mathbf{P}$ \\
\hline \multicolumn{7}{|l|}{ Age (years) } \\
\hline$<64$ & Reference & & & & & \\
\hline 64-76 & 0.865 & $0.597-1.252$ & 0.442 & & & \\
\hline$>76$ & 0.701 & $0.385-1.278$ & 0.246 & & & \\
\hline \multicolumn{7}{|l|}{ Tumour site } \\
\hline Npple/central & Reference & & & & & \\
\hline Upper-inner & 0.504 & $0.245-1.034$ & 0.062 & & & \\
\hline Lower-inner & 0.545 & $0.216-1.375$ & 0.199 & & & \\
\hline Upper-outer & 0.415 & $0.217-0.795$ & 0.008 & & & \\
\hline Lower-outer & 0.627 & $0.279-1.409$ & 0.259 & & & \\
\hline Others & 0.975 & $0.538-1.767$ & 0.934 & & & \\
\hline \multicolumn{7}{|l|}{ Laterality } \\
\hline Left & Reference & & & & & \\
\hline Right & 1.094 & $0.797-1.501$ & 0.578 & & & \\
\hline \multicolumn{7}{|l|}{ Histology } \\
\hline Duct & Reference & & & & & \\
\hline Lobular & 2.147 & $1.33-3.465$ & 0.002 & 1.976 & $1.074-3.480$ & 0.0226 \\
\hline Duct+lobular & 0.834 & $0.306-2.27$ & 0.722 & 0.805 & $0.214-2.268$ & 0.7145 \\
\hline Others & 1.66 & $0.89-3.095$ & 0.111 & 1.7 & $0.753-3.545$ & 0.1774 \\
\hline \multicolumn{7}{|l|}{ Grade } \\
\hline Grade I & Reference & & & & & \\
\hline Grade2 & 2.403 & $|.4| 9-4.07 \mid$ & 0.001 & & & \\
\hline Grade3 & 2.904 & $1.691-4.986$ & $<0.001$ & & & \\
\hline Grade4 & 17.734 & $3.828-82.146$ & $<0.001$ & & & \\
\hline \multicolumn{7}{|c|}{ Summary stage } \\
\hline Local & Reference & & & & & \\
\hline Regional & 1 & $0-\operatorname{lnf}$ & 1 & & & \\
\hline Distant & $2.0284 E+10$ & $0-\operatorname{lnf}$ & 0.978 & & & \\
\hline \multicolumn{7}{|l|}{ T_stage } \\
\hline TI & Reference & & & & & \\
\hline T2 & 3.515 & $2.266-5.454$ & $<0.001$ & 1.349 & $0.820-2.241$ & 0.242 \\
\hline T3 & 9.44 & $5.57-15.999$ & $<0.001$ & 1.641 & $0.874-3.042$ & 0.118 \\
\hline T4 & 34.849 & $21.578-56.283$ & $<0.001$ & 2.514 & $1.326-4.757$ & 0.005 \\
\hline \multicolumn{7}{|l|}{ N_stage } \\
\hline No & Reference & & & & & \\
\hline NI & 7.678 & $5.103-11.552$ & $<0.001$ & 4.193 & $2.646-6.747$ & $<0.001$ \\
\hline N2 & 11.726 & $6.805-20.208$ & $<0.001$ & 9.777 & $5.096-18.519$ & $<0.001$ \\
\hline N3 & 22.84 & |3.525-38.57| & $<0.001$ & 9.348 & $4.675-18.516$ & $<0.001$ \\
\hline \multicolumn{7}{|c|}{ Surg prim site } \\
\hline No & Reference & & & & & \\
\hline Yes & 0.014 & $0.01-0.02$ & $<0.001$ & 0.022 & $0.015-0.035$ & $<0.001$ \\
\hline
\end{tabular}


Table 3 (Continued).

\begin{tabular}{|c|c|c|c|c|c|c|}
\hline \multirow[t]{2}{*}{ Variables } & \multicolumn{3}{|c|}{ Univariate Logistic Regression } & \multicolumn{3}{|c|}{ Multivariate Logistic Regression } \\
\hline & OR & $95 \% \mathrm{Cl}$ & $\mathbf{P}$ & OR & $95 \% \mathrm{Cl}$ & $\mathbf{P}$ \\
\hline \multicolumn{7}{|c|}{ Tumour size (cm) } \\
\hline$<2$ & Reference & & & & & \\
\hline $2 \sim 5$ & 3.667 & $2.416-5.567$ & $<0.001$ & & & \\
\hline$>5$ & 12.18 & $7.785-19.056$ & $<0.001$ & & & \\
\hline \multicolumn{7}{|c|}{ Brain_metastasis } \\
\hline No & Reference & & & & & \\
\hline Yes & 0 & $0-\operatorname{lnf}$ & 0.979 & & & \\
\hline \multicolumn{7}{|c|}{ Liver_metastasis } \\
\hline No & Reference & & & & & \\
\hline Yes & 0 & $0-6.782 e+304$ & 0.975 & & & \\
\hline \multicolumn{7}{|c|}{ Lung_metastasis } \\
\hline No & Reference & & & & & \\
\hline Yes & 0 & $0-\operatorname{lnf}$ & 0.976 & & & \\
\hline \multicolumn{7}{|l|}{ Subtype } \\
\hline HR-/HER2- & Reference & & & & & \\
\hline HR-/HER2+ & 1.468 & $0.563-3.826$ & 0.432 & & & \\
\hline HR+/HER2- & 1.406 & $0.7|I-2.78|$ & 0.327 & & & \\
\hline HR+/HER2+ & 2.112 & $0.98 \mathrm{I}-4.544$ & 0.056 & & & \\
\hline \multicolumn{7}{|l|}{ ER } \\
\hline Negative & Reference & & & & & \\
\hline Positive & 1.884 & $1.061-3.328$ & 0.03 & 2.617 & I.487-4.886 & 0.002 \\
\hline \multicolumn{7}{|l|}{ PR } \\
\hline Negative & Reference & & & & & \\
\hline Positive & 1.074 & $0.738-1.562$ & 0.709 & & & \\
\hline \multicolumn{7}{|l|}{ HER2 } \\
\hline Negative & Reference & & & & & \\
\hline Positive & 1.398 & $0.949-2.059$ & 0.09 & & & \\
\hline
\end{tabular}

Abbreviations: HER2, human epidermal growth factor receptor 2; ER, estrogen receptor; PR, progesterone receptor.

factors for $\mathrm{BC}$ prognosis (Table 4, Figure 4C). A nomogram based on these variables was constructed to predict the prognosis of $\mathrm{BC}$ in the training cohort. It can be seen from the nomogram that age, grade, tumor stage, and surgery at the primary site had the greatest impact on $\mathrm{BC}$ prognosis (Figure 4D). We can obtain the survival probability of each patient at 1,3 , and 5 years. The $\mathrm{C}$-indexes of the 1-year, 3 year, and 5-year OS in the training cohort were 0.856 (95\% $\mathrm{CI}=0.814-0.898), 0.846(95 \% \mathrm{CI}=0.828-0.865)$, and 0.823 (95\% CI $=0.800-0.846)$. The C-indexes of 1-year, 3 -year, and 5-year OS in the validation cohort were 0.855 $(95 \% \mathrm{CI}=0.793-0.917), 0.811(95 \% \mathrm{CI}=0.779-0.844)$, and $0.804(95 \% \mathrm{CI}=0.776-0.832)$. The ROCs were used to evaluate the discrimination of the nomogram (Figures 5A and B). Calibration curves were used to evaluate the calibration of the nomogram in the training and validation cohorts. The abscissa represents the nomogram-predicted probability of the OS, and the ordinate represents the actual OS. In the training cohort, the nomogram had high calibration in predicting the 3-year OS, whereas in the validation cohort, the nomogram had high calibration in predicting the 1-, 3-, and 5-year OS (Figures 5C-H). Survival analyses based on each variable in the $\mathrm{BC}$ cohort showed significant differences between the groups (Figure S1). 


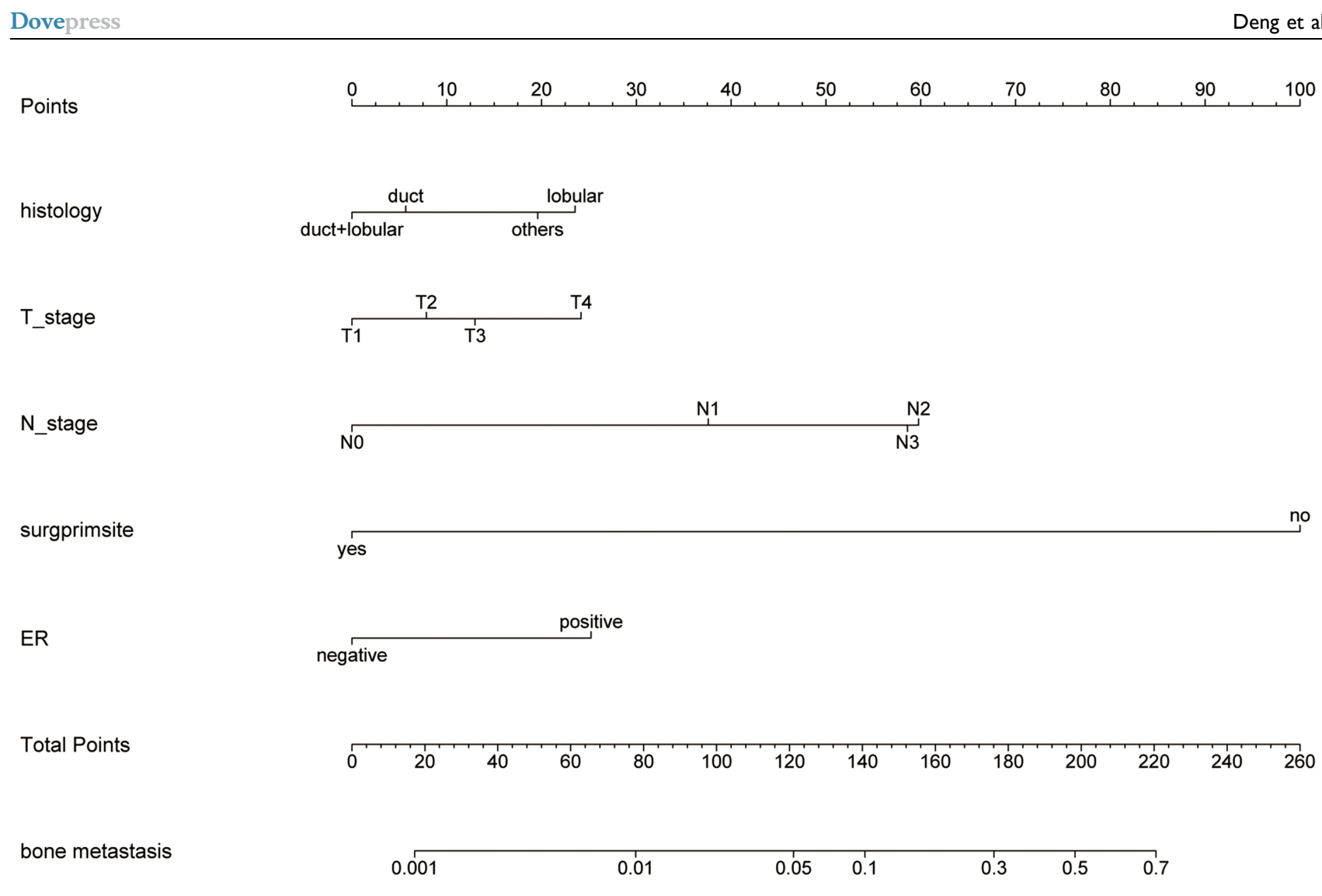

Figure 2 The nomogram to predict BCBM. Five independent risk factors were used to construct the nomogram; the total point can be obtained by summing the scores of each variable, and the probability of BCBM for each patient can be predicted.

Abbreviation: ER, estrogen.

\section{The Established and Validated Prediction Model for the Prognosis of BCBM}

To study the prognostic factors of patients with BCBM, 223 patients were included in the study cohort (Table 4). Univariate analysis and LASSO regression (Figures 6A and $\mathrm{B}$ ) were performed, and histology, primary site surgery, T-stage, N-stage, BC subtype, and PR were included in the multivariate Cox proportional hazard model. The results showed that the above variables were independent risk factors for the prognosis of BCBM (Table 5, Figure 6C). The nomogram based on these variables showed that both BC subtype and histology had a significant impact on the prognosis of BCBM (Figure 6D). We have calculated the survival probability of each patient at 1,3 , and 5 years. The C-index was used to evaluate the discrimination of the nomogram. In the training cohort, the C-indexes of 1-, 3-, and 5-year OS were 0.804 (95\% CI = $0.696-0.912), 0.761$ (95\% CI $=0.688-0.834)$, and 0.793 (95\% CI $=0.709-0.877)$, respectively. In the validation cohort, the C-indexes of 1-, 3-, and 5-year OS were 0.706 (95\% CI $=0.516-0.896), 0.633(95 \% \mathrm{CI}=0.462-0.804)$, and $0.723(95 \% \mathrm{CI}=0.544-0.902)$. It can be seen that the prediction model had a better predictive performance for 1- and 5-year OS, but the prediction accuracy of the 3-year OS was poor. The ROCs were used to evaluate the discrimination of the nomogram (Figures $7 \mathrm{~A}$ and $\mathrm{B}$ ). Calibration curves were used to calibrate the nomogram. It can be seen that in the training cohort, the nomogram had a high prediction accuracy for the 3-year OS, but the prediction accuracy for the 1- and 5-year OS was poor. However, in the validation cohort, the nomogram had higher accuracy in predicting 1-, 3-, and 5-year OS (Figures 7C-H). Survival analyses based on each variable in the BCBM cohort showed significant differences between the groups (Figure S2).

\section{Discussion}

With the advancement of local and systemic treatment techniques, the mortality rate of breast cancer has shown a downward trend. ${ }^{8,19,20}$ In this study, we describe the survival characteristics of patients with newly diagnosed breast cancer. We found that in the entire study cohort, the median survival time of patients with breast cancer was more than 100 months. This finding is consistent with the 


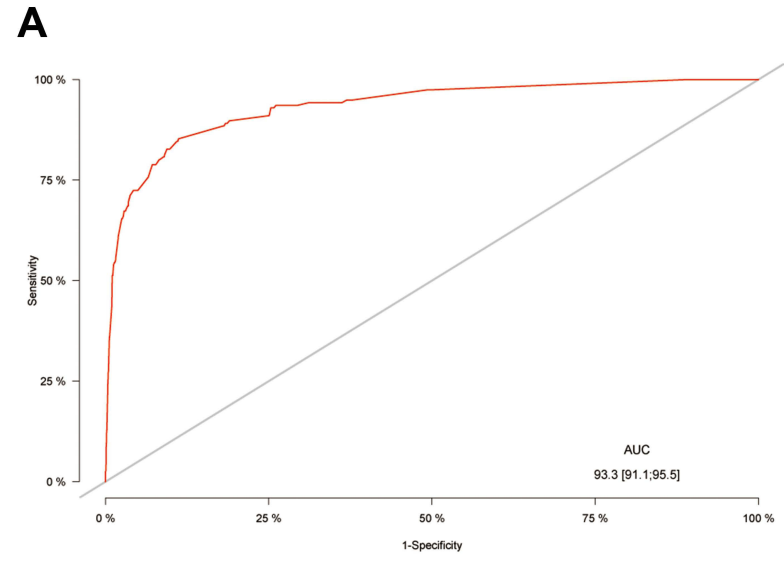

C

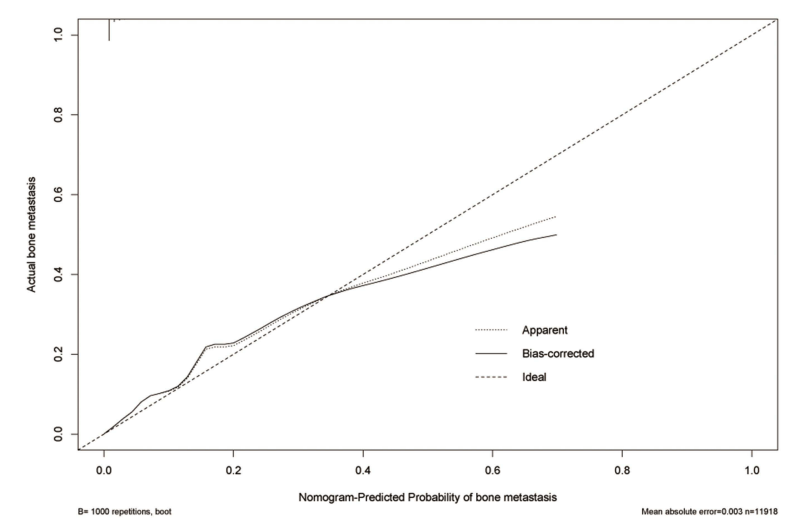

B

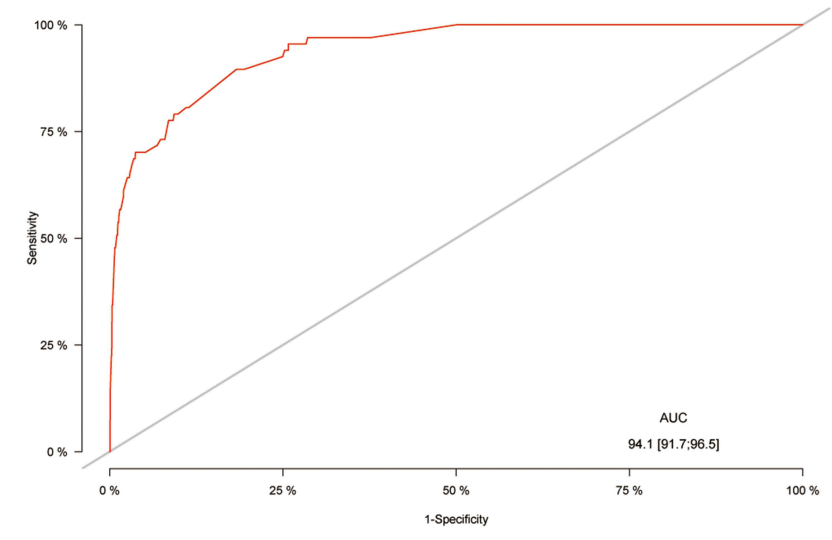

D

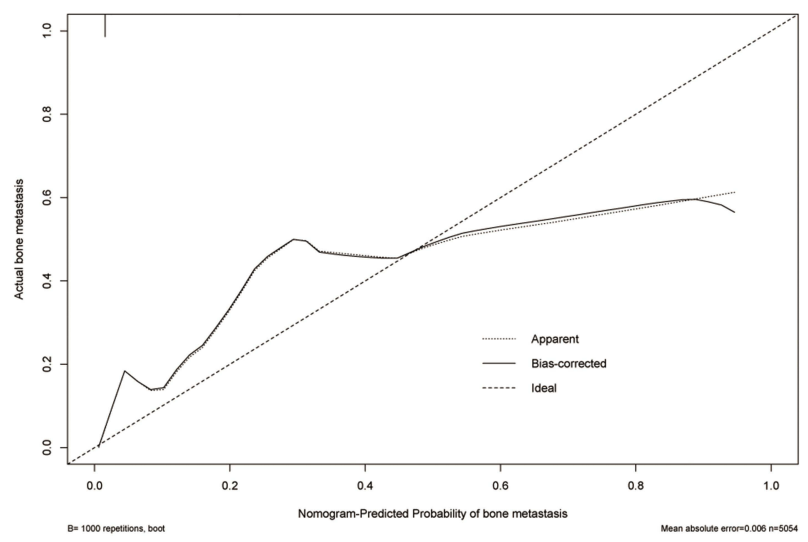

Figure 3 The evaluation of the nomogram to predict BCBM. The ROC curve in the training cohort (A) and the validation cohort (B). The C-index is represented by the area under the curve. The calibration curve in the training cohort (C) and the validation cohort (D). The $C$-index is represented by the area under the curve. The closer the curve is to the dashed line with a slope of $45^{\circ}$, the higher the calibration of the nomogram.

epidemiological characteristics of the disease. We also found that the patient's age, tumor stage, tumor grade, and whether or not to undergo surgery at the primary site was performed are all important factors affecting the prognosis of breast cancer patients. In addition, T-stage, $\mathrm{N}$-stage, and ER status are also factors that affect the prognosis of breast cancer. This result is consistent with the results reported in the previous literature. ${ }^{21-23}$

With the prolongation of survival time, the prevention and treatment of distant metastasis of $\mathrm{BC}$ have received more attention. Currently, bone metastasis accounts for $70 \%$ of distant BC metastases. Although we excluded patients with multiple distant metastases, there was a selection bias. However, in this study, 223 patients with bone metastasis accounted for $73.6 \%$ of all BC patients with distant metastasis; this is similar to previous reports. Breast cancer bone metastases not only lead to the occurrence of SREs but also seriously affect the median life expectancy of the patients. $^{24}$ Therefore, identifying the risk factors for breast cancer bone metastasis is of great significance for the early detection and treatment of bone metastasis and improving patient prognosis.

The mechanisms underlying breast cancer bone metastasis have not been fully elucidated. Various factors such as omega-3 long-chain polyunsaturated fatty acids, BC subtypes, race, and age play important roles in this process. Ethnicity is an independent risk factor of the occurrence of breast cancer bone metastasis and affects the prognosis of BC. ${ }^{25-28}$ This suggests that the bone metastasis and prognosis of breast cancer are race heterogeneous. Therefore, the risk and prognostic prediction module based on a specific race were more accurate and individualized in predicting the outcome for that race. In this study, we selected Asian females as the research participants and excluded cases of multiple organ metastases.

Through the prediction model of BCBM, we found that histology, T_stage, N_stage, primary site surgery, and ER 
A

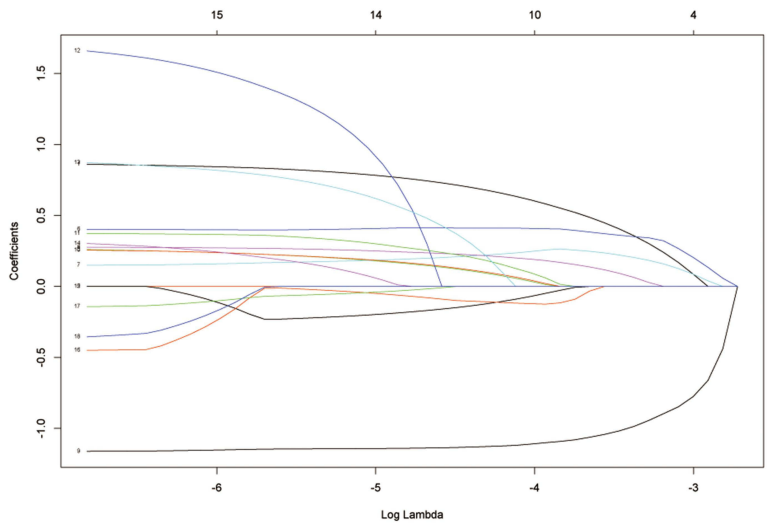

C

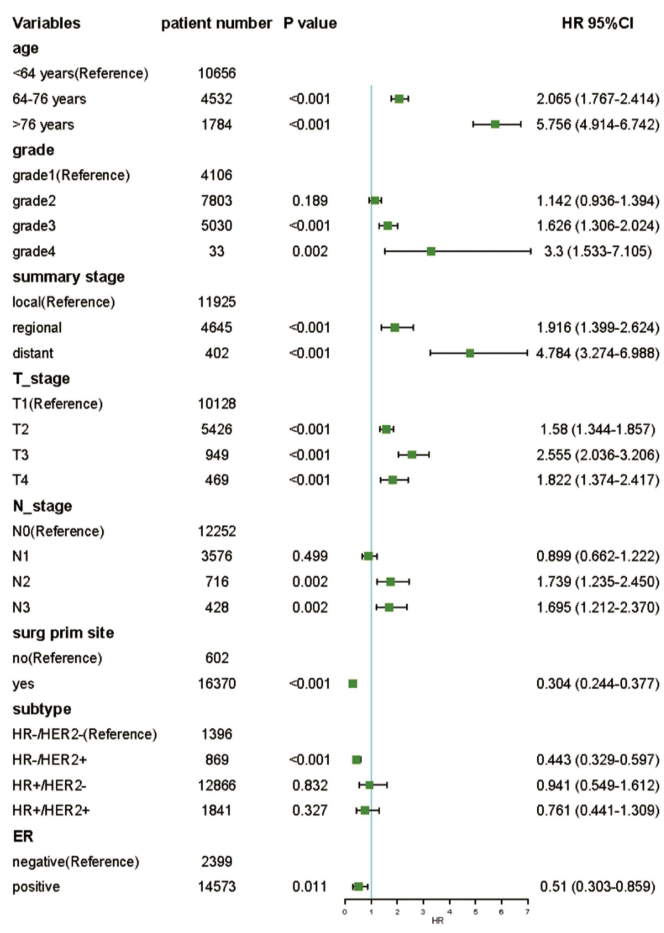

B

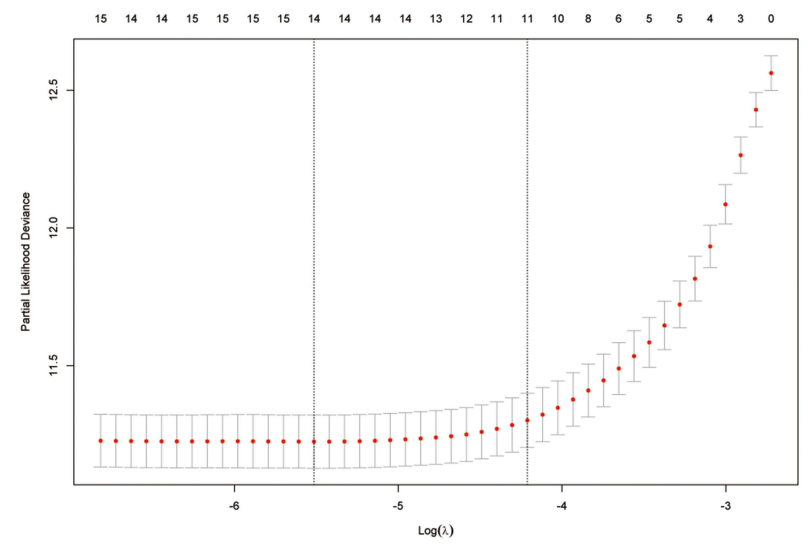

D

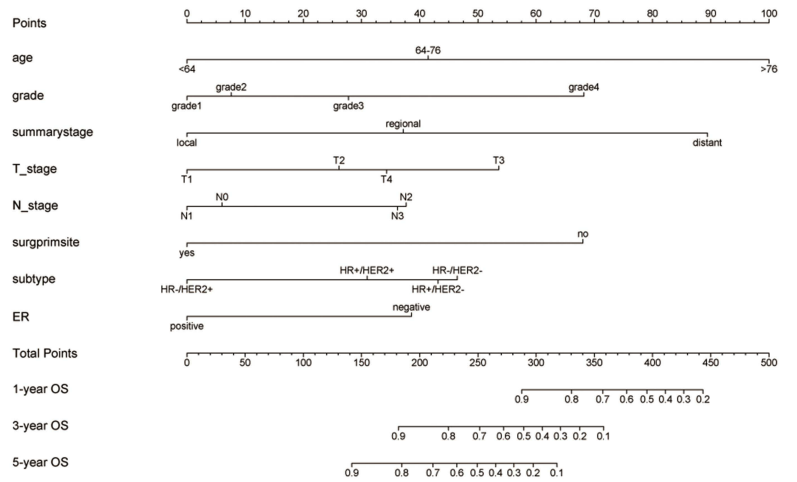

Figure 4 The screening of the prognostic variables of BC and the construction of the nomogram. (A and $\mathbf{B}$ ) LASSO regression was used to screen variables. (C) Forest plots were used to delineate the prognostic factors of BC. (D) The nomogram to predict the prognosis of BC in I, 3 , and 5 years.

Abbreviations: HER2, human epidermal growth factor receptor 2; ER, estrogen receptor.

were all independent risk factors for BM in BC. The nomogram that was constructed based on our prediction model revealed that surgery of the primary site and $\mathrm{N}$-stage were the main risk factors for $\mathrm{BM}$ in $\mathrm{BC}$. The risk of bone metastases is much higher in patients without primary site surgery and in patients with the $\mathrm{N} 3$ stage disease. Therefore, we recommend that surgery of the primary site be performed as far as possible for resectable breast cancer as this may reduce the incidence of bone metastasis. By histological type, the model predicts infiltrating lobular carcinoma to be more likely to have bone metastasis; this is consistent with previous research results. ${ }^{29}$ It has been reported that ER+ and ER- breast cancers have different biological pathways in the development of BCBM. Compared with ER- breast cancer, ER+ breast cancer is more likely to metastasize to the bone; this may be related to the activation of different signaling pathways. ${ }^{30,31}$ However, there are also reports in the literature that in the process of breast cancer bone metastasis, the homing of breast cancer cells is unrelated to their ER status. ${ }^{32}$ Therefore, further clinical and experimental studies are required to confirm the role of ER in the BCBM process. 
Table 4 Univariate and Multivariate Cox Regression Analysis of Breast Cancer in Training Cohort

\begin{tabular}{|c|c|c|c|c|}
\hline \multirow[t]{2}{*}{ Variables } & \multicolumn{2}{|c|}{ Univariate Cox Regression } & \multicolumn{2}{|c|}{ Multivariate Cox Regression } \\
\hline & HR $(95 \% \mathrm{Cl})$ & $\mathbf{P}$ & HR (95\% Cl) & $\mathbf{P}$ \\
\hline \multicolumn{5}{|l|}{ Age (years) } \\
\hline$<64$ & Reference & & & \\
\hline 64-76 & $1.708(1.465-1.991)$ & $<0.001$ & $2.065(1.767-2.414)$ & $<0.001$ \\
\hline$>76$ & $5.103(4.392-5.929)$ & $<0.001$ & $5.756(4.914-6.742)$ & $<0.001$ \\
\hline \multicolumn{5}{|l|}{ Tumour site } \\
\hline Npple/central & Reference & & & \\
\hline Upper-inner & $0.604(0.457-0.799)$ & $<0.001$ & & \\
\hline Lower-inner & $0.75(0.534-1.054)$ & 0.097 & & \\
\hline Upper-outer & $0.586(0.456-0.752)$ & $<0.001$ & & \\
\hline Lower-outer & $0.643(0.465-0.888)$ & 0.007 & & \\
\hline Others & $0.815(0.64 \mid-1.038)$ & 0.098 & & \\
\hline \multicolumn{5}{|l|}{ Laterality } \\
\hline Left & Reference & & & \\
\hline Right & $0.971(0.856-1.101)$ & 0.644 & & \\
\hline \multicolumn{5}{|l|}{ Histology } \\
\hline Duct & Reference & & & \\
\hline Lobular & $1.091(0.849-1.403)$ & 0.495 & & \\
\hline Duct+lobular & $1.019(0.719-1.443)$ & 0.916 & & \\
\hline Others & $1.376(1.06-1.784)$ & 0.016 & & \\
\hline \multicolumn{5}{|l|}{ Grade } \\
\hline Gradel & Reference & & & \\
\hline Grade2 & $1.428(1.177-1.733)$ & $<0.001$ & $1.142(0.936-1.394)$ & 0.189 \\
\hline Grade3 & $2.575(2.13-3.114)$ & $<0.001$ & $1.626(1.306-2.024)$ & $<0.001$ \\
\hline Grade4 & $5.09(2.381-10.879)$ & $<0.001$ & $3.3(1.533-7.105)$ & 0.002 \\
\hline \multicolumn{5}{|c|}{ Summary stage } \\
\hline Local & Reference & & & \\
\hline Regional & $2.52(2.201-2.886)$ & $<0.001$ & $1.916(1.399-2.624)$ & $<0.001$ \\
\hline Distant & $15.318(|2.6| 8-18.596)$ & $<0.001$ & $4.784(3.274-6.988)$ & $<0.001$ \\
\hline \multicolumn{5}{|l|}{ T_stage } \\
\hline TI & Reference & & & \\
\hline T2 & $2.324(2.009-2.688)$ & $<0.001$ & $1.58(1.344-1.857)$ & $<0.001$ \\
\hline T3 & $4.848(3.966-5.925)$ & $<0.001$ & $2.555(2.036-3.206)$ & $<0.001$ \\
\hline $\mathrm{T} 4$ & $9.676(7.797-12.007)$ & $<0.001$ & $1.822(1.374-2.417)$ & $<0.001$ \\
\hline \multicolumn{5}{|l|}{ N_stage } \\
\hline No & Reference & & & \\
\hline NI & $2.054(1.774-2.379)$ & $<0.001$ & $0.899(0.662-1.222)$ & 0.499 \\
\hline N2 & $4.004(3.242-4.945)$ & $<0.001$ & $1.739(1.235-2.450)$ & 0.002 \\
\hline N3 & $7.15(5.788-8.833)$ & $<0.001$ & $1.695(1.212-2.370)$ & 0.002 \\
\hline \multicolumn{5}{|c|}{ Surg prim site } \\
\hline No & Reference & & & \\
\hline Yes & $0.109(0.092-0.129)$ & $<0.001$ & $0.304(0.244-0.377)$ & $<0.001$ \\
\hline
\end{tabular}


Table 4 (Continued).

\begin{tabular}{|c|c|c|c|c|}
\hline \multirow[t]{2}{*}{ Variables } & \multicolumn{2}{|c|}{ Univariate Cox Regression } & \multicolumn{2}{|c|}{ Multivariate Cox Regression } \\
\hline & HR (95\% Cl) & $\mathbf{P}$ & HR (95\% Cl) & $\mathbf{P}$ \\
\hline \multicolumn{5}{|c|}{ Tumour size (cm) } \\
\hline$<2$ & Reference & & & \\
\hline $2 \sim 5$ & $2.33(2.016-2.692)$ & $<0.001$ & & \\
\hline$>5$ & $5.685(4.779-6.764)$ & $<0.001$ & & \\
\hline \multicolumn{5}{|c|}{ Bone_metastasis } \\
\hline No & Reference & & & \\
\hline Yes & $9.578(7.503-12.228)$ & $<0.001$ & & \\
\hline \multicolumn{5}{|c|}{ Brain_metastasis } \\
\hline No & Reference & & & \\
\hline Yes & $19.134(6.15-59.531)$ & $<0.001$ & & \\
\hline \multicolumn{5}{|c|}{ Liver_metastasis } \\
\hline No & Reference & & & \\
\hline Yes & $13.659(7.535-24.76)$ & $<0.001$ & & \\
\hline \multicolumn{5}{|c|}{ Lung_metastasis } \\
\hline No & Reference & & & \\
\hline Yes & $9.049(5.6-14.624)$ & $<0.001$ & & \\
\hline \multicolumn{5}{|l|}{ Subtype } \\
\hline HR-/HER2- & Reference & & & \\
\hline HR-/HER2+ & $0.497(0.372-0.665)$ & $<0.001$ & $0.443(0.329-0.597)$ & $<0.001$ \\
\hline HR+/HER2- & $0.368(0.3 \mid 2-0.434)$ & $<0.001$ & $0.941(0.549-1.612)$ & 0.832 \\
\hline HR+/HER2+ & $0.402(0.316-0.512)$ & $<0.001$ & $0.76 I(0.44 \mid-1.309)$ & 0.327 \\
\hline \multicolumn{5}{|l|}{ ER } \\
\hline Negative & Reference & & & \\
\hline Positive & $0.455(0.395-0.525)$ & $<0.001$ & $0.51(0.303-0.859)$ & 0.011 \\
\hline \multicolumn{5}{|l|}{ PR } \\
\hline Negative & Reference & & & \\
\hline Positive & $0.526(0.462-0.599)$ & $<0.001$ & & \\
\hline \multicolumn{5}{|l|}{ HER2 } \\
\hline Negative & Reference & & & \\
\hline Positive & $1.007(0.851-1.193)$ & 0.933 & & \\
\hline
\end{tabular}

Abbreviations: HER2, human epidermal growth factor receptor 2; ER, estrogen receptor; PR, progesterone receptor.

It can be seen from the prognosis model of breast cancer that age, grade, summary stage, T_stage, N_stage, primary site surgery, BC subtype, and ER are all independent risk factors that affect the OS of $\mathrm{BC}$ patients. Our results were consistent with findings presented in the existing literature: ${ }^{33-35}$ the older the patient, the higher the tumor grade, and the worse the prognosis. The $\mathrm{BC}$ subtype is significantly related to the prognosis of breast cancer, and the survival rate of triple negative breast cancer (TNBC) patients is significantly lower than that of non-TNBC patients. ${ }^{23,25}$ Therefore, we suggest that treatment should be carefully selected for patients with TNBC. Surgery can be applied to the primary site, but the decision must be considered carefully when it comes to metastatic lesions. 
A

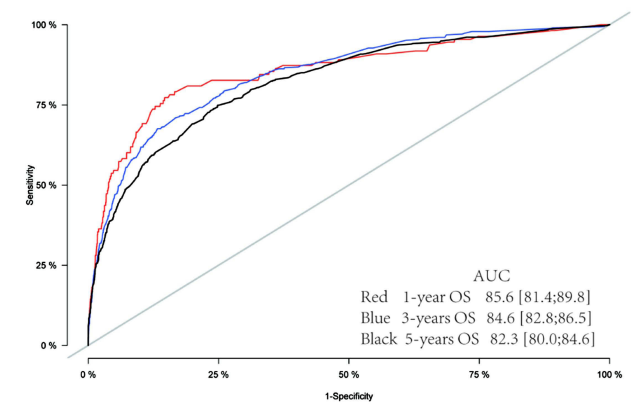

C

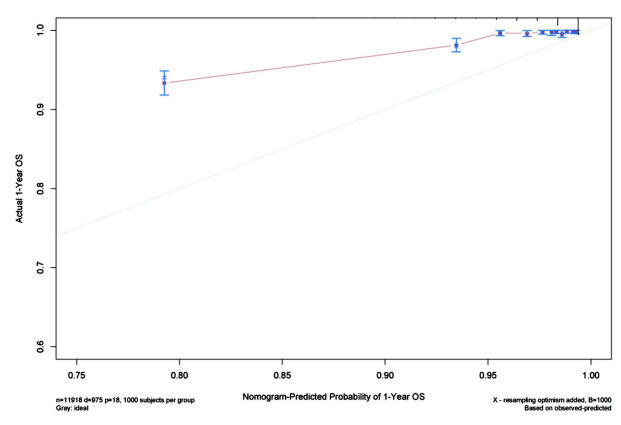

\section{E}

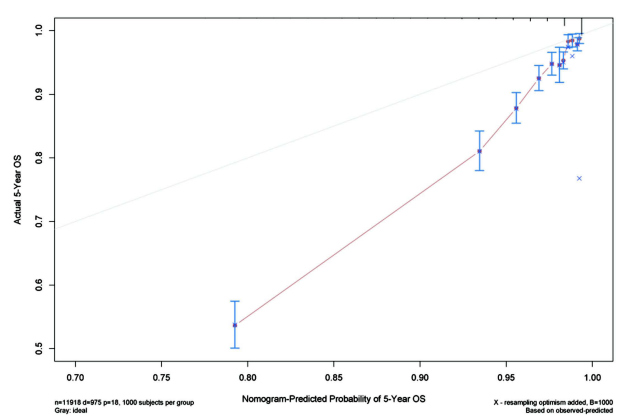

G

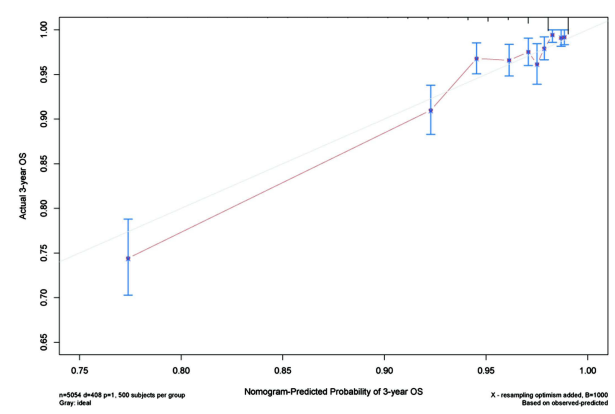

B

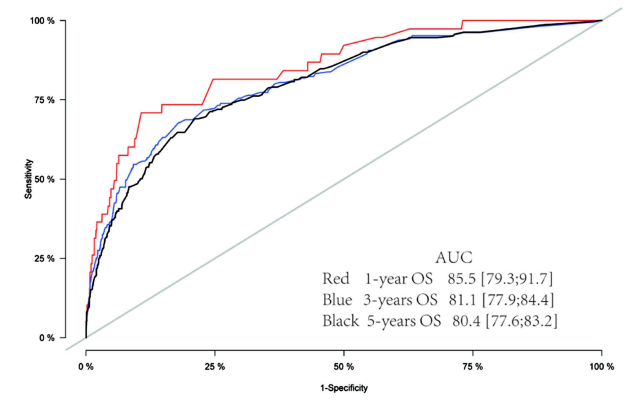

D

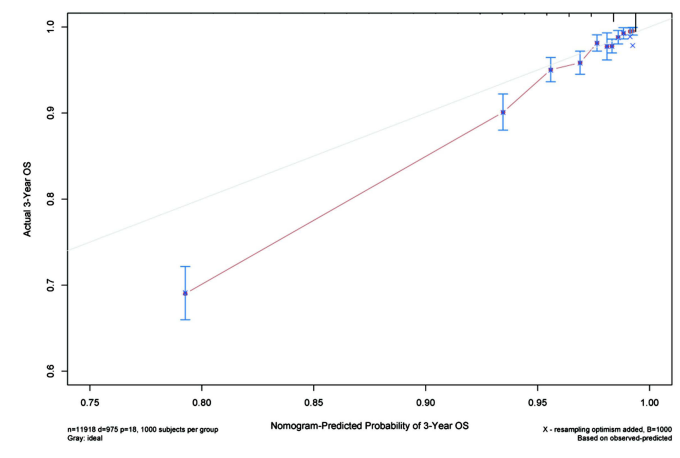

F

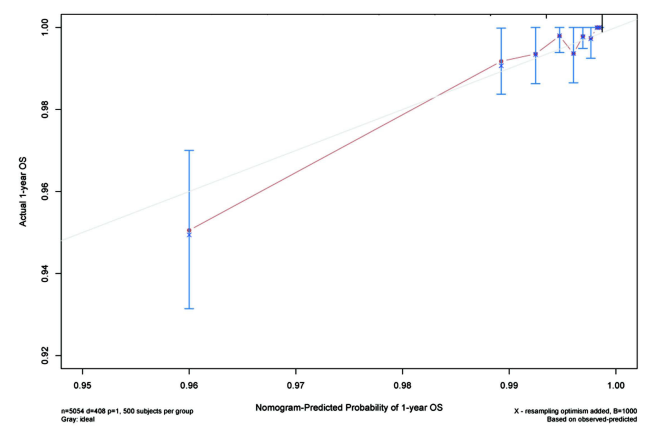

H

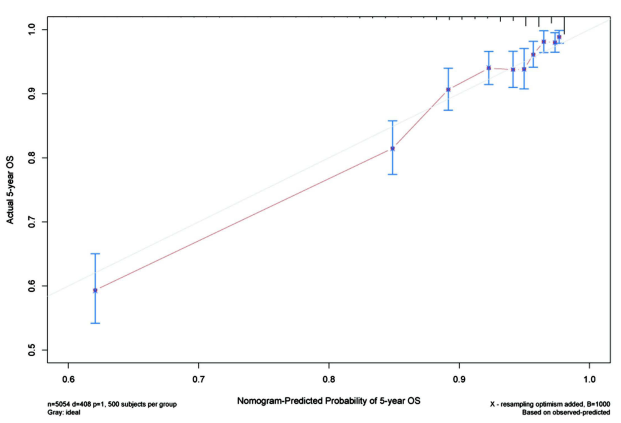

Figure 5 The evaluation of the nomogram to predict the prognosis of BC. The ROC curve in the training cohort (A) and the validation cohort (B) in I, 3, and 5 years. The C-index is represented by the area under the curve. The calibration curves in the training cohort (C-E) and the validation cohort (F-H) in I, 3 , and 5 years. The $\mathbf{C}$-index was represented by the area under the curve. The closer the curve is to the dashed line with a slope of $45^{\circ}$, the higher the calibration of the nomogram. 
A

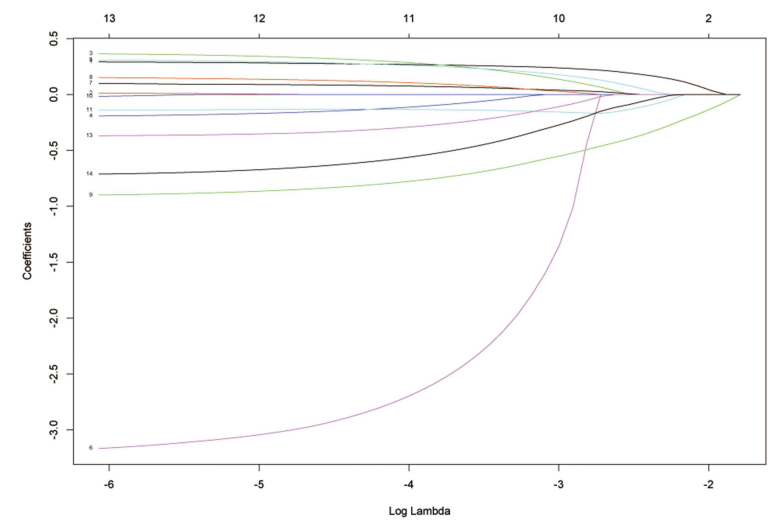

C

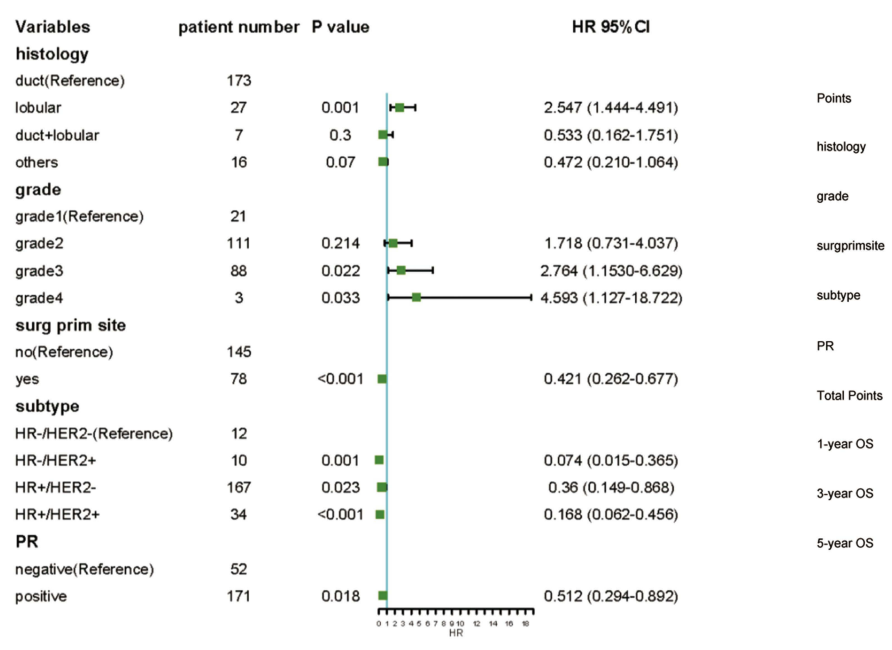

B

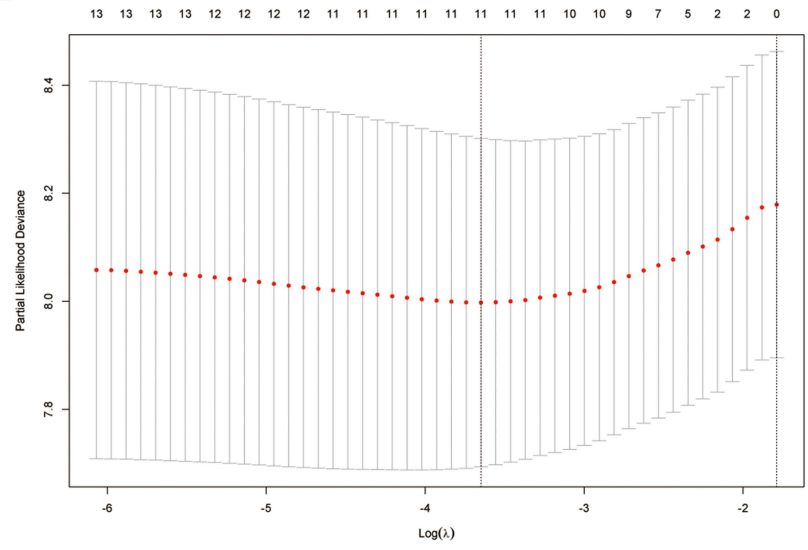

D

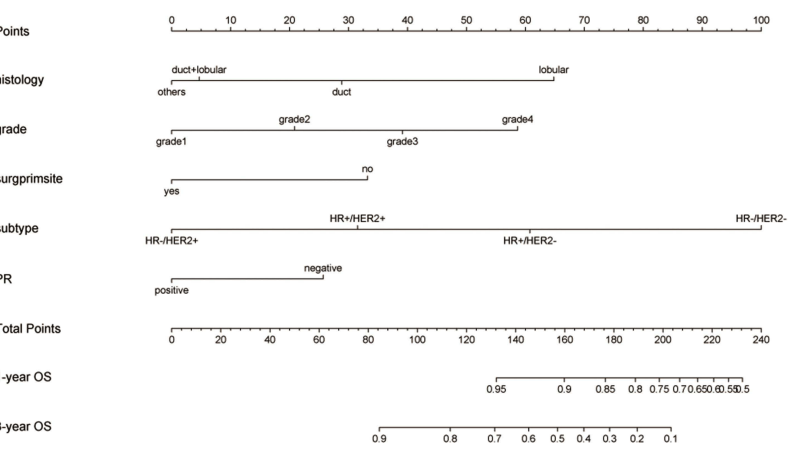

$\begin{array}{llllllllll}0.9 & 0.8 & 0.7 & 0.6 & 0.5 & 0.4 & 0.3 & 0.2 & 0.1\end{array}$

Figure 6 The screening of the prognostic variables of BCBM and the construction of the nomogram. (A and B) LASSO regression was used to screen variables. (C) Forest plots were used to delineate the prognostic factors of BCBM. (D) The nomogram to predict the prognosis of BCBM in I, 3 , and 5 years. Abbreviations: HER2, human epidermal growth factor receptor 2; PR, progesterone receptor.

Patients with multiple distant metastases tend to be treated using relatively conservative methods such as chemotherapy, endocrine therapy, and immunotherapy. However, it remains controversial which treatment method should be used for patients with bone-only metastases. Therefore, for breast cancer patients with bone-only metastases, it is important to clarify the prognostic risk factors and predict survival time because this is related to the choice of treatment. The accurate prognosis of BCBM is important for subsequent treatment selection. For example, under the premise of meeting the surgical indications, relatively aggressive treatment measures are adopted for patients who are expected to have a long survival time and relatively conservative treatment methods for patients who have a short survival time. In this study, we found that histology, primary site surgery, $\mathrm{T}$ _stage, $\mathrm{N}$ _stage, $\mathrm{BC}$ subtype, and PR were independent risk factors for OS in BCBM. The proportion of infiltrating ductal carcinoma in breast cancer is high, but the prognosis of infiltrating lobular carcinoma is worse than that of infiltrating ductal carcinoma. This may be related to the fact that infiltrating lobular carcinoma being hormone-mediated, common in the elderly, polycentric, and often found at advanced stages. In addition, invasive lobular carcinoma is mostly ER/PR positive and HER2 negative that often presents as large tumors with ill-defined boundaries and a unique metastasis pattern involving the gastrointestinal tract and peritoneum. ${ }^{36}$ Consistent with previous studies, N3-stage tumors, no primary site surgery, and TNBC are also factors for poor prognosis. In addition, the prognosis of breast 
Table 5 Univariate and Multivariate Cox Regression Analysis of BCBM in Training Cohort

\begin{tabular}{|c|c|c|c|c|}
\hline \multirow[t]{2}{*}{ Variables } & \multicolumn{2}{|c|}{ Univariate Cox Regression } & \multicolumn{2}{|c|}{ Multivariate Cox Regression } \\
\hline & HR (95\% Cl) & $\mathbf{P}$ & HR (95\% Cl) & $\mathbf{P}$ \\
\hline \multicolumn{5}{|l|}{ Age (years) } \\
\hline$<64$ & Reference & & & \\
\hline 64-76 & $1.691(1.033-2.768)$ & 0.037 & & \\
\hline$>76$ & $1.783(0.799-3.979)$ & 0.158 & & \\
\hline \multicolumn{5}{|l|}{ Tumour site } \\
\hline Npple/central & Reference & & & \\
\hline Upper-inner & $0.526(0.208-1.334)$ & 0.176 & & \\
\hline Lower-inner & $3.142(0.839-11.774)$ & 0.089 & & \\
\hline Upper-outer & $0.799(0.366-1.746)$ & 0.574 & & \\
\hline Lower-outer & $0.859(0.269-2.746)$ & 0.798 & & \\
\hline Others & $0.781(0.383-1.59)$ & 0.495 & & \\
\hline \multicolumn{5}{|l|}{ Laterality } \\
\hline Left & Reference & & & \\
\hline Right & $1.631(1.029-2.585)$ & 0.037 & & \\
\hline \multicolumn{5}{|l|}{ Histology } \\
\hline Duct & Reference & & & \\
\hline Lobular & $1.974(1.077-3.617)$ & 0.028 & $2.547(1.444-4.491)$ & 0.001 \\
\hline Duct+lobular & $0.788(0.192-3.234)$ & 0.741 & $0.533(0.162-1.75 I)$ & 0.3 \\
\hline Others & $0.256(0.062-1.05)$ & 0.058 & $0.472(0.210-1.064)$ & 0.07 \\
\hline \multicolumn{5}{|l|}{ Grade } \\
\hline Gradel & Reference & & & \\
\hline Grade2 & $1.38(0.489-3.893)$ & 0.543 & $1.718(0.73 \mid-4.037)$ & 0.214 \\
\hline Grade3 & $1.78(0.629-5.033)$ & 0.277 & $2.764(1.1530-6.629)$ & 0.022 \\
\hline Grade4 & $4.674(1.04 I-20.997)$ & 0.044 & $4.593(1.127-18.722)$ & 0.033 \\
\hline \multicolumn{5}{|c|}{ Summary stage } \\
\hline Local & Reference & & & \\
\hline Regional & $18.042(2.28|-| 42.72 \mid)$ & 0.006 & & \\
\hline Distant & NA (NA-NA) & NA & & \\
\hline \multicolumn{5}{|l|}{ T_stage } \\
\hline TI & Reference & & & \\
\hline $\mathrm{T} 2$ & $0.954(0.469-1.94)$ & 0.896 & & \\
\hline T3 & $1.161(0.526-2.56)$ & 0.712 & & \\
\hline T4 & $1.61(0.788-3.29)$ & 0.192 & & \\
\hline \multicolumn{5}{|l|}{ N_stage } \\
\hline No & Reference & & & \\
\hline NI & $0.679(0.366-1.261)$ & 0.22 & & \\
\hline N2 & $0.562(0.235-1.342)$ & 0.195 & & \\
\hline N3 & $1.418(0.684-2.942)$ & 0.348 & & \\
\hline \multicolumn{5}{|c|}{ Surg prim site } \\
\hline No & Reference & & & \\
\hline Yes & $0.518(0.307-0.875)$ & 0.014 & $0.421(0.262-0.677)$ & $<0.001$ \\
\hline
\end{tabular}

(Continued) 
Table 5 (Continued).

\begin{tabular}{|c|c|c|c|c|}
\hline \multirow[t]{2}{*}{ Variables } & \multicolumn{2}{|c|}{ Univariate Cox Regression } & \multicolumn{2}{|c|}{ Multivariate Cox Regression } \\
\hline & HR (95\% Cl) & $\mathbf{P}$ & HR (95\% Cl) & $\mathbf{P}$ \\
\hline \multicolumn{5}{|c|}{ Tumour size (cm) } \\
\hline$<2$ & Reference & & & \\
\hline $2 \sim 5$ & $1.018(0.502-2.063)$ & 0.96 & & \\
\hline$>5$ & $1.238(0.605-2.534)$ & 0.559 & & \\
\hline \multicolumn{5}{|l|}{ Subtype } \\
\hline HR-/HER2- & Reference & & & \\
\hline HR-/HER2+ & $0.043(0.005-0.356)$ & 0.004 & $0.074(0.015-0.365)$ & 0.001 \\
\hline HR+/HER2- & $0.165(0.072-0.378)$ & 0 & $0.36(0.149-0.868)$ & 0.023 \\
\hline $\mathrm{HR}+/ \mathrm{HER} 2+$ & $0.12(0.043-0.338)$ & 0 & $0.168(0.062-0.456)$ & $<0.001$ \\
\hline \multicolumn{5}{|l|}{ ER } \\
\hline Negative & Reference & & & \\
\hline Positive & $0.599(0.287-1.25)$ & 0.172 & & \\
\hline \multicolumn{5}{|l|}{ PR } \\
\hline Negative & Reference & & & \\
\hline Positive & $0.635(0.385-1.047)$ & 0.075 & $0.512(0.294-0.892)$ & 0.018 \\
\hline \multicolumn{5}{|l|}{ HER2 } \\
\hline Negative & Reference & & & \\
\hline Positive & $0.57(0.292-1.113)$ & 0.1 & & \\
\hline
\end{tabular}

Abbreviations: HER2, human epidermal growth factor receptor 2; ER, estrogen receptor; PR, progesterone receptor.

cancer with PR- is also poor, which may be related to the insensitivity of this type of breast cancer to chemotherapy. Therefore, these factors should be fully considered when making subsequent treatment plans based on the nomogram to develop a more accurate and individualized treatment for patients.

\section{Limitations}

This study has certain limitations. First, the information on the operation provided by the SEER database is not sufficiently comprehensive because it does not provide detailed operation-related information such as surgical indications, specific surgical procedures, and complications. Second, there is no detailed information about the location of the metastasis such as whether bone metastasis occurs in the axial bone or the limb bone, which may lead to a bias in the study. Third, some patients were excluded due to missing data, which may have led to selection bias. Finally, this study lacks validation from external data, and we will use our data to validate these prediction models in further studies.

\section{Conclusion}

In summary, this study constructed a prediction model for bone metastasis in Asian females with breast cancer through population-based analysis, determined independent risk factors for bone metastasis in breast cancer, and constructed a nomogram. An important and effective model for predicting OS in patients with breast cancer has also been constructed to clarify the prognostic factors of patients with BCBM. This study provides the basis for clinicians and patients to prevent SREs and provides a new approach for BCBM patients to weigh the risks and benefits of surgery for metastatic lesions. 
A

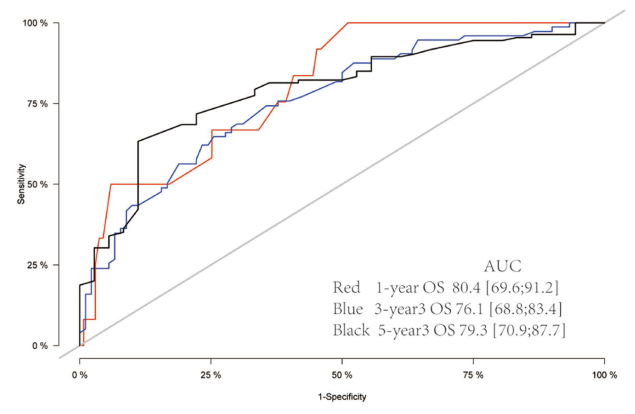

C

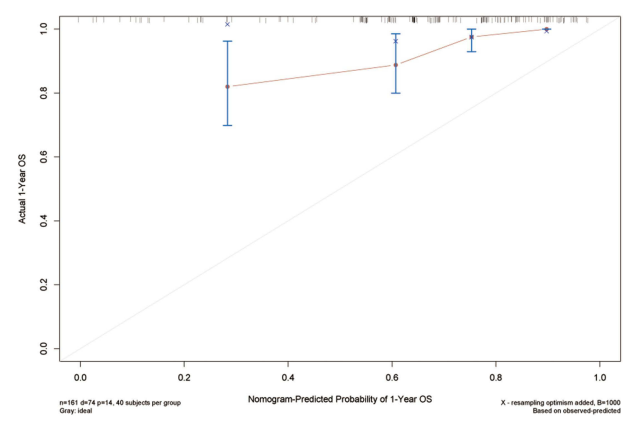

E

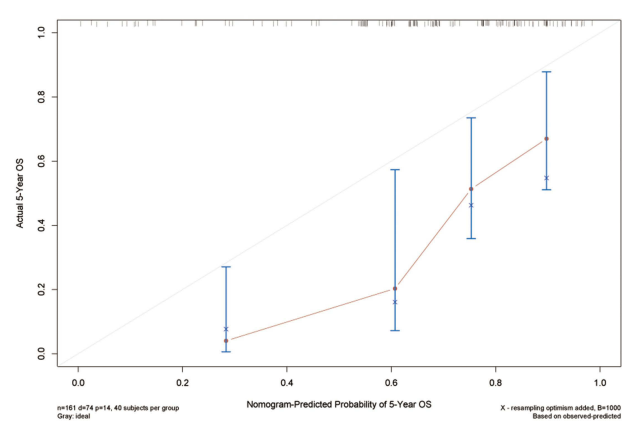

G

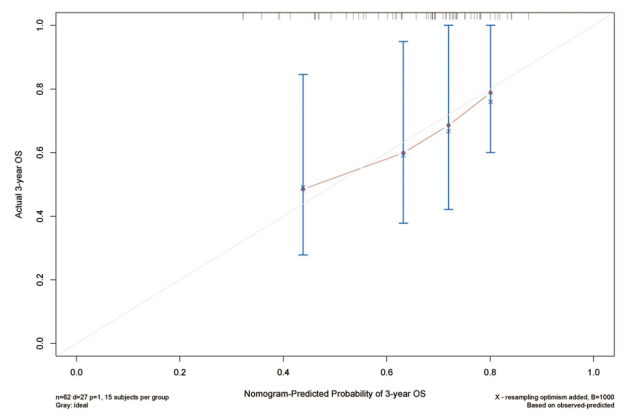

B

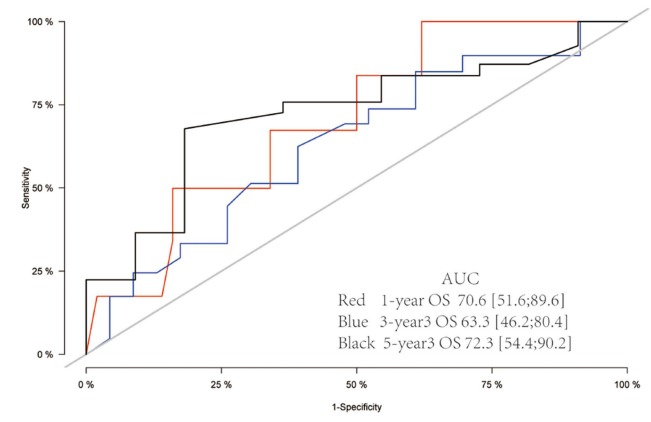

D

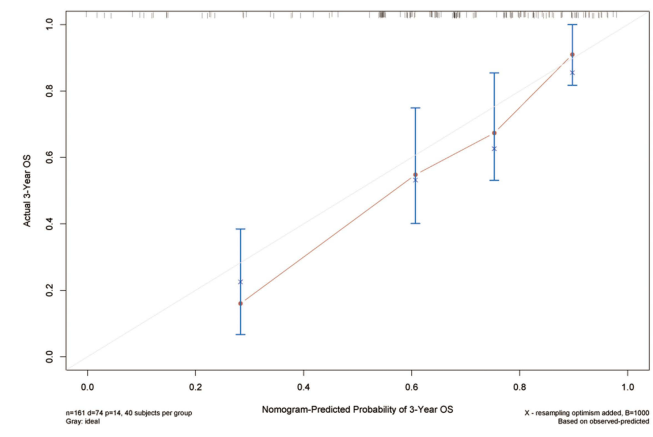

$\mathbf{F}$

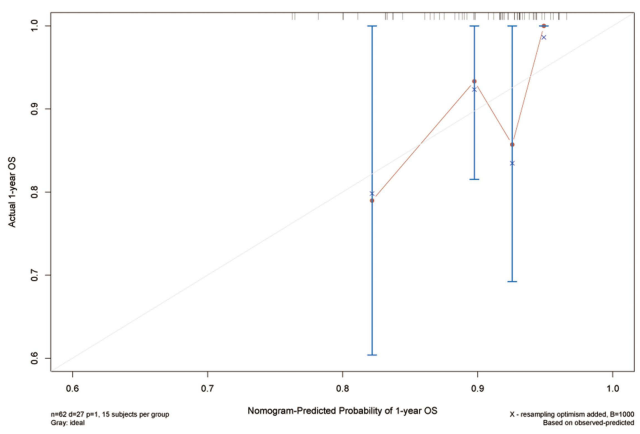

H

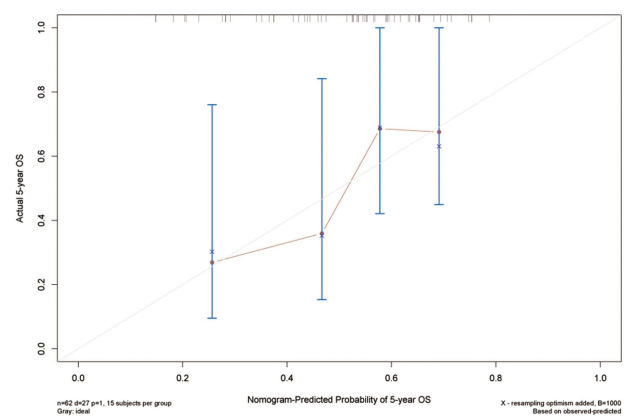

Figure 7 The evaluation of the nomogram to predict the prognosis of BCBM. The ROC curve in the training cohort (A) and the validation cohort (B) in I, 3, and 5 years. The $\mathrm{C}$-index is represented by the area under the curve. The calibration curve in the training cohort $(\mathbf{C}-\mathbf{E})$ and the validation cohort $(\mathbf{F}-\mathbf{H})$ in $\mathbf{I}, 3$, and 5 years. The C-index if represented by the area under the curve. The closer the curve is to the dashed line with a slope of $45^{\circ}$, the higher the calibration of the nomogram. 


\section{Author Contributions}

All authors contributed to data analysis, drafting or revising the article, have agreed on the journal to which the article will be submitted, gave final approval of the version to be published, and agree to be accountable for all aspects of the work.

\section{Funding}

This study was supported by Henan Province traditional Chinese Medicine scientific research special project (2018ZY2116).

\section{Disclosure}

All authors declare that no competing financial interests exist and that no conflict of interest exists.

\section{References}

1. Fan L, Strasser-Weippl K, Li JJ, et al. Breast cancer in China. Lancet Oncol. 2014;15(7):e279-e289. doi:10.1016/S1470-2045(13)70567-9

2. Liang Y, Zhang H, Song X, et al. Metastatic heterogeneity of breast cancer: molecular mechanism and potential therapeutic targets. Semin Cancer Biol. 2020;60:14-27. doi:10.1016/j.semcancer.2019.08.012

3. Shemanko CS, Cong Y, Forsyth A. What is breast in the bone? Int $J$ Mol Sci. 2016;17(10):1764. doi:10.3390/ijms 17101764

4. Coleman RE, Croucher PI, Padhani AR, et al. Bone metastases. Nat Rev Dis Primers. 2020;6(1):83. doi:10.1038/s41572-020-00216-3

5. Bidwell BN, Slaney CY, Withana NP, et al. Silencing of Irf7 pathways in breast cancer cells promotes bone metastasis through immune escape. Nat Med. 2012;18(8):1224-1231. doi:10.1038/nm.2830

6. Jiang P, Gao W, Ma T, et al. CD137 promotes bone metastasis of breast cancer by enhancing the migration and osteoclast differentiation of monocytes/macrophages. Theranostics. 2019;9(10):2950 2966. doi:10.7150/thno.29617

7. Yang M, Liu C, Yu X. Skeletal-related adverse events during bone metastasis of breast cancer: current status. Discov Med. 2019;27 (149):211-220.

8. Harbeck N, Gnant M. Breast cancer. Lancet. 2017;389(10074):11341150. doi:10.1016/S0140-6736(16)31891-8

9. Liu D, Wu J, Lin C, et al. Breast subtypes and prognosis of breast cancer patients with initial bone metastasis: a Population-Based Study. Front Oncol. 2020;10:580112. doi:10.3389/fonc.2020.580112

10. Li X, Zhang X, Liu J, et al. Prognostic factors and survival according to tumour subtype in women presenting with breast cancer bone metastases at initial diagnosis: a SEER-based study. BMC Cancer. 2020;20(1):1102. doi:10.1186/s12885-020-07593-8

11. Balachandran VP, Gonen M, Smith JJ, et al. Nomograms in oncology: more than meets the eye. Lancet Oncol. 2015;16(4):e173-e180. doi:10.1016/S1470-2045(14)71116-7

12. Liu X, Zhang D, Liu Z, et al. Deep learning radiomics-based prediction of distant metastasis in patients with locally advanced rectal cancer after neoadjuvant chemoradiotherapy: a multicentre study. EBioMedicine. 2021;69:103442. doi:10.1016/j.ebiom.2021.103442

13. Dong Y, Que L, Jia Q, et al. Predicting reintervention after thoracic endovascular aortic repair of Stanford type B aortic dissection using machine learning. Eur Radiol. 2021. doi:10.1007/s00330-021-07849-2

14. Zhao W, Wu L, Zhao A, et al. A nomogram for predicting survival in patients with de novo metastatic breast cancer: a population-based study. BMC Cancer. 2020;20(1):982. doi:10.1186/s12885-02007449-1
15. Cronin KA, Ries LA, Edwards BK. The Surveillance, Epidemiology, and End Results (SEER) program of the national cancer institute. Cancer. 2014;120(Suppl 23):3755-3757. doi:10.1002/cncr.29049

16. Liu Y, Wu L, Ao H, et al. Prognostic implications of autophagyassociated gene signatures in non-small cell lung cancer. Aging. 2019;11(23):11440-11462. doi:10.18632/aging.102544

17. Harrell FE Jr, Lee KL, Mark DB. Multivariable prognostic models: issues in developing models, evaluating assumptions and adequacy, and measuring and reducing errors. Stat Med. 1996;15(4):361-387. doi:10.1002/(SICI)1097-0258(19960229)15:4<361::AIDSIM168 $>3.0 . \mathrm{CO} ; 2-4$

18. Xu D, Zhang K, Li M, et al. Prognostic nomogram for resected pancreatic adenocarcinoma: a TRIPOD-compliant retrospective long-term survival analysis. World J Surg. 2020;44(4):1260-1269. doi:10.1007/s00268-019-05325-z

19. Moezian GSA, Javadinia SA, Sales SS, et al. Oral silymarin formulation efficacy in management of AC-T protocol induced hepatotoxicity in breast cancer patients: a randomized, triple blind, placebo-controlled clinical trial. $J$ Oncol Pharm Pract. 2021:10781552211006182. doi:10.1177/10781552211006182

20. Salek R, Dehghani M, Mohajeri SA, et al. Amelioration of anxiety, depression, and chemotherapy related toxicity after crocin administration during chemotherapy of breast cancer: a double blind, randomized clinical trial. Phytother Res. 2021;35(9):5143-5153. doi: $10.1002 /$ ptr. 7180

21. Engel J, Weichert W, Jung A, et al. Lymph node infiltration, parallel metastasis and treatment success in breast cancer. Breast. 2019;48:16. doi:10.1016/j.breast.2019.07.008

22. Tosello G, Torloni MR, Mota BS, et al. Breast surgery for metastatic breast cancer. Cochrane Database Syst Rev. 2018;3(3):Cd011276. doi:10.1002/14651858.CD011276.pub2

23. Li X, Yang J, Peng L, et al. Triple-negative breast cancer has worse overall survival and cause-specific survival than non-triple-negative breast cancer. Breast Cancer Res Treat. 2017;161(2):279-287. doi:10.1007/s10549-016-4059-6

24. Zhang H, Zhu W, Biskup E, et al. Incidence, risk factors and prognostic characteristics of bone metastases and skeletal-related events (SREs) in breast cancer patients: a systematic review of the real world data. J Bone Oncol. 2018;11:38-50. doi:10.1016/j.jbo.2018.01.004

25. Sakhuja S, Deveaux A, Wilson LE, et al. Patterns of de-novo metastasis and breast cancer-specific mortality by race and molecular subtype in the SEER population-based dataset. Breast Cancer Res Treat. 2021;186(2):509-518. doi:10.1007/s10549-020-06007-4

26. Gao T, Shao F. Risk factors and prognostic factors for inflammatory breast cancer with bone metastasis: a population-based study. $J$ Orthop Surg. 2021;29(2):23094990211000144. doi:10.1177/ 23094990211000144

27. Goupille C, Frank PG, Arbion F, et al. Low levels of omega-3 longchain polyunsaturated fatty acids are associated with bone metastasis formation in premenopausal women with breast cancer: a Retrospective Study. Nutrients. 2020;12(12):3832. doi:10.3390/ nu12123832

28. Gong Y, Zhang J, Ji P, et al. Incidence proportions and prognosis of breast cancer patients with bone metastases at initial diagnosis. Cancer Med. 2018;7(8):4156-4169. doi:10.1002/cam4.1668

29. Purushotham A, Shamil E, Cariati M, et al. Age at diagnosis and distant metastasis in breast cancer-a surprising inverse relationship. Eur J Cancer. 2014;50(10):1697-1705. doi:10.1016/j.ejca.2014. 04.002

30. Arciero CA, Guo Y, Jiang R, et al. ER(+)/HER2(+) breast cancer has different metastatic patterns and better survival than ER(-)/HER2(+) breast cancer. Clin Breast Cancer. 2019;19(4):236-245. doi:10.1016/ j.clbc.2019.02.001

31. Hayashi N, Iwamoto T, Qi Y, et al. Bone metastasis-related signaling pathways in breast cancers stratified by estrogen receptor status. $J$ Cancer. 2017;8(6):1045-1052. doi:10.7150/jca.13690 
32. Allocca G, Hughes R, Wang N, et al. The bone metastasis niche in breast cancer-potential overlap with the haematopoietic stem cell niche in vivo. J Bone Oncol. 2019;17:100244. doi:10.1016/j. jbo.2019.100244

33. Zhou X, Zheng Z, Li Y, et al. The clinical features and prognosis of patients with mucinous breast carcinoma compared with those with infiltrating ductal carcinoma: a population-based study. BMC Cancer. 2021;21(1):536. doi:10.1186/s12885-021-08262-0

34. Huang Z, Zhou X, Tong Y, et al. Surgery for primary tumor benefits survival for breast cancer patients with bone metastases: a large cohort retrospective study. BMC Cancer. 2021;21(1):222. doi:10.1186/s12885-021-07964-9
35. Erić I, Petek erić A, Kristek J, et al. Breast cancer in young women: pathologic and immunohistochemical features. Acta Clin Croat. 2018;57(3):497-502. doi:10.20471/acc.2018.57.03.13

36. Thomas M, Kelly ED, Abraham J, et al. Invasive lobular breast cancer: a review of pathogenesis, diagnosis, management, and future directions of early stage disease. Semin Oncol. 2019;46(2):121-132. doi:10.1053/j.seminoncol.2019.03.002

\section{Publish your work in this journal}

The International Journal of General Medicine is an international, peer-reviewed open-access journal that focuses on general and internal medicine, pathogenesis, epidemiology, diagnosis, monitoring and treatment protocols. The journal is characterized by the rapid reporting of reviews, original research and clinical studies across all disease areas. The manuscript management system is completely online and includes a very quick and fair peer-review system, which is all easy to use. Visit http://www.dovepress.com/ testimonials.php to read real quotes from published authors. 